\title{
Research
}

\section{Understanding the Mechanisms of Collective Decision Making in Ecological Restoration: An Agent-Based Model of Actors and Organizations}

\author{
$\underline{\text { Cristy Watkins }}^{1}, \underline{\text { Dean Massey }}^{2}, \underline{\text { Jeremy Brooks }}^{3}, \underline{\text { Kristen Ross }}^{2}$ and Moira L. Zellner ${ }^{2}$
}

\begin{abstract}
Ecological restoration, particularly in urban contexts, is a complex collective decision-making process that involves a diversity of stakeholders and experts, each with their own perceptions and preferences about what landscapes should and can look like, how to get them to the desired state, and on what timeline. We investigate how structural and behavioral factors may influence collective decision making in the context of ecological restoration, with the purpose of establishing general relationships between management styles (defined by structural and behavioral factors of the organization) and decision outcomes. Informed by existing literature on collective decision making and by empirical data from the Chicago Wilderness region, we present a stylized agent-based model that maps out and simulates the processes by which individuals within restoration organizations communicate, discuss, and ultimately make a decision. Our study examines how structural and behavioral characteristicsincluding: (a) the number of actors and groups involved in decision making, (b) the frequency and type of interactions among actors, (c) the initial setup of positions and respect, (d) outside information, and (e) entrenchment and cost of dissent-lead to or prohibit group convergence in terms of collective position, variation in position across actors, and final decision strategies. We found that formal meetings and group leaders are important facilitators of convergence, especially when multiple groups are present, new information is introduced in the process, and participants are polarized around an issue. Also, intergroup interactions are particularly important for overall convergence. Position entrenchment slows the convergence process and increases the need for decision strategies involving outside intervention. Cost of dissent can reinforce these effects. Our study formalizes collective decision-making processes within the context of ecological restoration, establishes generalizable relationships between these processes and decision outcomes, and provides a foundation for further empirical and modeling research.
\end{abstract}

Key Words: agent-based modeling; Chicago Wilderness; collective decision making; ecological restoration

\section{INTRODUCTION}

Ecological restoration, particularly in urban contexts, is a complex collective decision-making process. Diverse goals for land use can lead to conflict around resource management choices. For example, how much trail construction, invasive species removal, or tree planting should occur in a forest preserve depends on different stakeholders' perceptions of the ecological status of the preserve and land-use priorities. Further, managing natural resources in urban areas is complicated by limited space and historic —often unknowneffects of human alterations to the landscape (e.g., infrastructure development and subsequent alterations to hydrology, habitat, and other ecosystem functions). Diverse opinions about goals and appropriate restoration strategies, and the ways in which goals and techniques are discussed across stakeholder groups (both within and outside of the decision-making group), can lead to conflict within an organization and between the organization and the public. Sometimes this conflict results in unsuccessful or subpar management (White et al. 2009). Understanding how collective decision-making processes occur will provide insights that can enhance and support successful ecological restoration practices.
Previous research has evaluated collective decision making related to common pool resource extraction and has often focused on how stakeholders set goals and criteria for maintaining resource supply and condition (see Grimble and Wellard 1997). This literature concerns how to: (1) bring people to the table, for example with the use of participatory modeling (Becu et al. 2008, Jones et al. 2009); (2) consider a diverse array of knowledge, perspectives, and values (Beratan 2007, Hermans et al. 2007, Steyaert et al. 2007); and (3) increase stakeholder participation (e.g., Lal et al. 2001, Herath and Prato 2006, Castella 2009, Hayati et al. 2009). These studies help us understand how to create and increase participation in collective common pool resource management, but they do not illustrate how group structure and participant interactions influence collective decision making within already established conservation organizations. Furthermore, with the exception of Regan et al. (2006), most studies on common pool resource management lack generalization and formalization of the dynamics of collective decision making (Poteete and Ostrom 2008), and they tend to focus on extractive rather than nonextractive collective management decisions (e.g., ecological restoration) (an exception being Ito et al. 2008). We seek to formalize the

\footnotetext{
${ }^{1}$ The Field Museum, Chicago, Illinois, USA, ${ }^{2}$ University of Illinois at Chicago, ${ }^{3}$ University of Illinois at Urbana-Champaign
} 
mechanisms by which structural and behavioral factors influence the interactions among land managers, staff, and volunteers within an established ecological restoration organization, and to formulate general relationships between these factors and decision outcomes. We have focused our study on collective decision making about oak woodland restoration projects in urban settings because: (1) these ecosystems are in decline and are of global conservation significance (Glennemeier 2004), and (2) restoration techniques can be especially contentious because more diverse opinions about land use and management practices exist at the human/nature interface (e.g., Gobster and Hull 2000, Crane et al. in press).

To examine relationships between collective decision-making processes and outcomes, we created a stylized computational model of relevant actors involved in groups within conservation organizations, interacting during a season to influence each other's position relative to a specific ecological restoration practice. We informed our model by combining literature on collective decision making and existing stylized models of consensus building with richer ethnographic observations of, and semistructured interviews with, regional restoration decision makers of organizations restoring oak woodland in Chicago Wilderness. The Chicago Wilderness is a consortium of over 260 organizations whose primary goal is the conservation, restoration, and management of biodiversity on over 150,000 ha of open space in the greater Chicago metropolitan area (Moskovits 2004). The stylized model we present here is one component of a larger, interdisciplinary project seeking to reveal the institutional arrangements (norms, rules, and strategies) that guide collective decision-making processes and explain how different arrangements may lead to different biodiversity outcomes in 10 organizations within Chicago Wilderness. We use the Institutional Analysis and Development (IAD) framework (Ostrom 2007) to define and categorize the variety of actors, resources, and interactions in our model. The IAD framework allows for the analysis and comparison of collaborative, interorganizational processes (Imperial 1999) and rules of engagement in natural resource management partnerships (Hardy and Koontz 2009). The framework has been used to understand the conditions under which successful resource management institutions are most likely to emerge (e.g., Gibson et al. 2000, Andersson 2006, Chhatre and Agrawal 2009).

Our model is built on an agent-based platform. Agent-based modeling is well suited to explicitly represent the aspects that characterize the complexity of collective decision making: interaction among heterogeneous and autonomous actors across time and space (Janssen and Ostrom 2006, Ostrom 2007, Zellner 2008). The purpose of this stylized model is to organize theoretical and empirical information into formal descriptions of actor interactions during the process of collective decision making, and to explicitly link these interactions with decision outcomes. Our aim is to develop theory that explains a wide range of cases, rather than to represent the detailed reality of particular cases. We use the generalizations derived from the modeling to generate hypotheses and guide additional empirical research for the larger project in which the modeling is embedded. The use of literature and of empirical observations of Chicago Wilderness is focused on determining plausible mechanisms and parameter value ranges for the stylized model, and is consistent with current modeling practices and applications (e.g., Haefner 1996, Gilbert and Troitzsch 1999, Macy and Willer 2002, Goldstone and Janssen 2005, Robinson et al. 2007, Yang and Gilbert 2008, Delre et al. 2010, Railsback and Grimm 2012). We use our model to examine how the following affect decision processes and outcomes: (a) the number of actors and groups involved in decision making, (b) the frequency of interactions among actors, (c) the initial distribution of positions among actors and their respect for each other, (d) external information, and (e) entrenchment and cost of dissent. We assess simulation outcomes in terms of: (1) how actors' positions converge or what keeps them from doing so, (2) the value and variation of positions across the actors, and (3) the final decision strategies that occur (whole-group convergence, point-person consensus, outside arbiter).

We first describe our methodological approach and its foundation in theory and empirical observations, distilling the relevant features that guided model design and development. We follow with a description of the components and mechanisms of our model, simulations, and results. We conclude with a discussion of our findings in light of their contribution to generalizations about collective decision making in restoration organizations.

\section{METHODS: THEORETICAL AND EMPIRICAL FOUNDATIONS FOR MODELING COLLECTIVE DECISION MAKING}

\section{Study area}

Chicago Wilderness is a large-scale social-ecological system embedded in a major metropolitan area (Fig. 1). The 10 organizations used in this study were chosen to represent the diversity of groups within Chicago Wilderness membership (large county departments, public gardens, and small land trusts). These organizations are typically composed of diverse participants arranged in different working groups (e.g., volunteer stewards, staff biologists/ecologists, operational "on-the-ground" technicians). We seek to understand how diverse working groups create institutional arrangements and modes of interaction to obtain desired environmental management results, and in this way produce robust methodologies and recommendations for biodiversity conservation that are applicable to a variety of urban areas. A better understanding of the dynamics and outcomes of 
different models of ecological restoration planning should lead to strategies that allow for innovation while minimizing conflict and enhancing governance.

Fig. 1. Study areas within the Chicago Wilderness region. Source: Northeastern Illinois Planning Commission, Environment and Natural Resources Group (March 17, 2008).
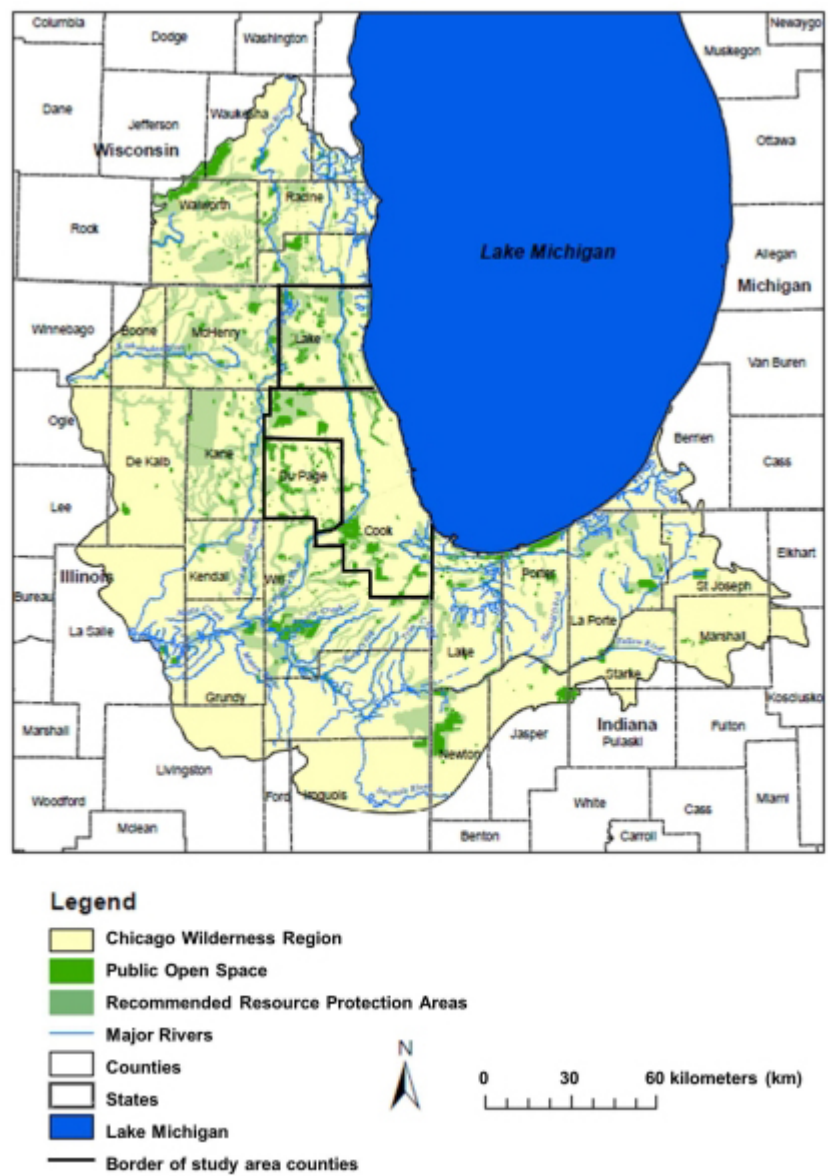

\section{Iterative model design}

We conducted an iterative process of literature review, data collection, and conceptual modeling to distill the main factors and mechanisms that should be present in a stylized model of collective decision making for ecological restoration. The literature identifies several important factors and mechanisms that affect collective deliberation and decision outcomes (described in detail in the following sections): (a) status (respect for others in the group as well as respect for one's own expertise in a subject area); (b) introduction of new information, ideas, or resources; and (c) a variety of decision strategies.
We supplemented the literature with empirical observations of Chicago Wilderness organizations. Guided by the IAD framework, we conducted semistructured, confidential interviews between March 2010 and March 2011 with over 50 restoration decision makers holding different positions and with varying authority in 10 different organizations within Chicago Wilderness. We also observed dozens of organization meetings and ecological restoration workdays. Interviews were transcribed and broad thematic codes were created (Glaser and Strauss 1967, Bernard 2005) using NVivo, a qualitative data analysis software (QSR International Pty Ltd. Version 9 2012). Subsets of the data were jointly coded to develop initial categories of rules of engagement and organizational structure, and to ensure validity and shared understanding. The data were further split among researchers with relevant expertise (e.g., anthropology, sociology). The empirical observations confirmed the relevance of the factors identified in the literature (a to c, above), and revealed the importance of two additional factors and mechanisms: (d) organization structure, and (e) the types and frequency of participant interactions within and between groups.

The above factors and mechanisms guided the construction of a base model that helped us establish some general relationships with collective decision-making outcomes, but which was limited in producing the variety of outcomes that are typically observed in Chicago Wilderness and other restoration organizations. We thus turned back to the literature and empirical observations, and identified psychological mechanisms with the potential to affect the collective process: (f) dissent and entrenchment. The following section conceptualizes all factors and mechanisms in detail. Where available, we include Chicago Wilderness examples to illustrate these factors (all names mentioned are coded pseudonyms).

\section{Modeling design guidelines}

\section{Organizational structure, composition, and roles}

Ethnographic observations revealed that the study organizations vary in size, and it is difficult to determine the number of participants involved in a specific decision-making event. All of the Chicago Wilderness organizations we modeled had three or fewer working groups (referred to as just "groups" hereafter) that regularly participated in the decisionmaking process at any given time. Within each organization there is a hierarchy of participants with varying power and/or responsibilities. All participants are involved in the decisionmaking process in some way, but some may act as "advisors" who may or may not be a part of the final decision, while others may have additional authority or represent the group to others and act as the official decision maker or "point person" (Argyres and Mui 2007, Taylor and Short 2009), as illustrated in the following interview excerpt: 
Is it consensus? No, well, there's a structure within each of the programs here. A hierarchical structure. Ultimately, if we don't come to a consensus, I mean, that's ZI's role as the manager."

(12/28/10, LC, land manager)

Our observations suggested that there are four basic types of interactions that can occur in Chicago Wilderness organizations and these are defined by when they take place and who is involved (Fig. 2). The interaction can involve only agents within the same group (intragroup interaction) or among two or three groups (intergroup interaction). Formal interactions (e.g., scheduled meetings) tend to occur at regular intervals, whereas casual interactions (e.g., e-mail, phone calls, talking in the hall, etc.) are spontaneous, more frequent, and do not follow a schedule. Formal intergroup interactions involve only point persons of the various groups within an organization. Formal intragroup interactions involve all the advisors and the point person in a single group. Ethnographic interviews indicated that whole-organization meetings (e.g., every advisor and point person) — formal or informal—are rare or nonexistent.

Fig. 2. Four interaction types: (a) intergroup formal indicates regular meetings only between point persons of each group; (b) intragroup formal indicates regular meetings among all members within their own group; (c) intergroup informal indicates casual exchanges among all members of different groups; and (d) intragroup informal indicates casual interactions of all members within their own group.

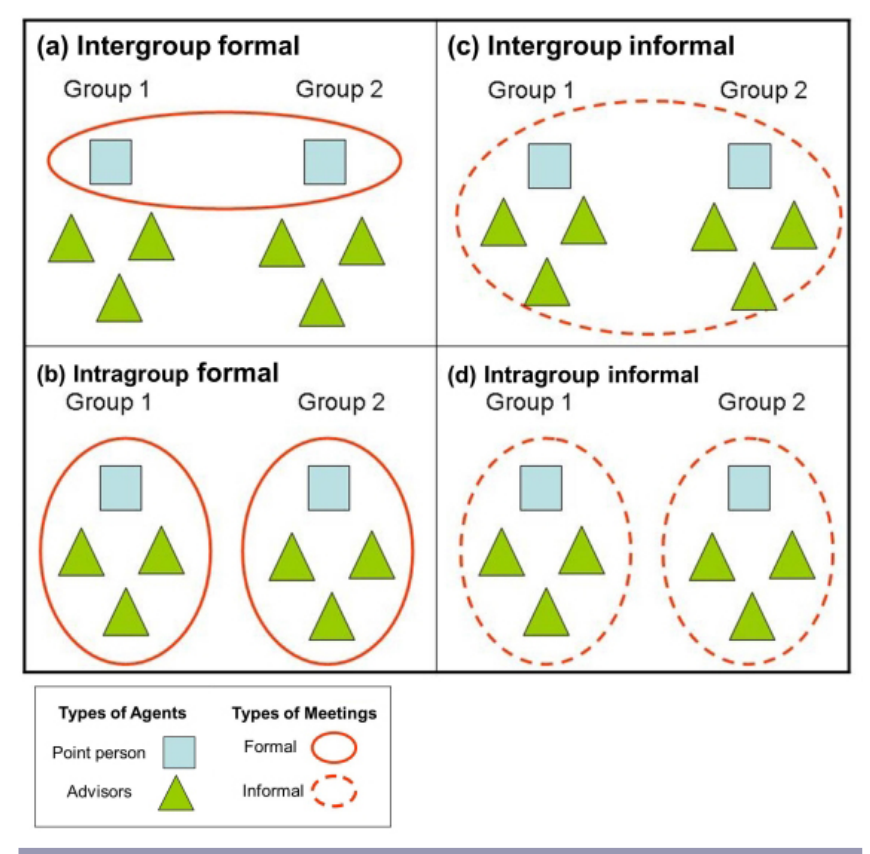

\section{Positions and respect}

Empirical observations of Chicago Wilderness organizations revealed that agents may have disparate opinions or positions about specific restoration strategies or techniques. Although Chicago Wilderness organizations participate in policy development, the collective deliberation in the groups we studied focused on the magnitude of application of a particular strategy within an already established policy supporting that strategy. For example, collective decision-making focused on how much of an invasive shrub should be removed during the season, rather than whether removal should occur or not, which is a decision that was already made at higher levels of the organization. Across all of the organizations, respondents referred to "differences in philosophy" or "variations in perceptions of risk" to explain the diversity of positions arising from their particular role or expertise within the organization. In the shrub-removal example, some agents were concerned about the potential impacts of shrub removal on other species, while others were concerned about potential disturbance to the soil without the proper follow-up, and still others were guided by the presence or absence of funds. "Restoration is not black and white," explained a decision maker (01/05/11, $\mathrm{AK}$, land manager); that is, within a range of possible options, multiple ("gray") opinions are possible and acceptable.

Findings in the literature also suggest that high status group members who are seen as knowledgeable and respectable can influence the position of others (Henrich and Gil-White 2001, Atran et al. 2002, Baumann and Bonner 2004, Ohtsubo and Masuchi 2004, See 2009). Status may be derived from positive social connections (Kilduff and Krackhardt 1994); perceived knowledge or expertise (Wittenbaum 1998, 2000); or one's role, physical appearance, socioeconomic standing, or other demographic traits (Thomas-Hunt et al. 2003). In line with prior work, we conceptualized each group member's opinion of the expertise of others as respect, a weight that is applied to each member's opinion or position (Davis et al. 1993, Davis 1996, Kerr and Tindale 2004, Regan et al. 2006, Ekel et al. 2008). According to the literature, lead decision makers tend to place more weight on their own position and advisors' position more similar to their own, than on dissimilar positions (Harvey et al. 2000, Yaniv and Kleinberger 2000). Our observations, however, indicated that agents can place greater respect (i.e., weight) on the position of others, even if they differ with their own, based on their appreciation for the effort or expertise of others. For example, one respondent admitted,

And I will say I don't agree with all the decisions. So [US is] pretty much making the decisions about what our monetary resources are. And he's also making decisions about where the intern resources are going and where the volunteer resources are going for the restoration. So US really is controlling that situation. And I have to admit when there's 
someone like US who's willing to put in as much time and effort as he does, then I'm willing to concede a whole lot to him.

(11/03/10, LO, volunteer)

Another respondent stated:

I supervise RI and NI3 in their areas. But I depend almost completely on their knowledge and their expertise to make the calls as far as biodiversity within what they control.

(01/10/10, LF, Director)

\section{External influences}

If we view groups as dynamic and interactive systems, we must pay attention not only to changes in positions based on interactions within and across groups, but also to the influence of external forces (e.g., particular individuals outside of the group; surrounding communities; the larger cultural, social, political and economic environment) (Arrow et al. 2000). Outside information can modify group members' positions and change the direction or pattern of the convergence process (Ekel et al. 2008, Maturo and Ventre 2010). For example, Chicago Wilderness members may attend workshops and trainings where they learn new scientific or technical information, or they can interact with and learn from persuasive individuals outside of the decision-making process. Many respondents described occasions when a management technique changed as a result of outside influences, such as networking with managers, visiting other sites, and pressure from special interest groups like birders, or simply from reading academic journals:

Just in the process of networking with other managers and visiting other sites, I realized that we could probably do this if we were to step into this carefully and so then we developed a technique to go in to our natural areas, into our woodlands, and use this particular machine to do the work.

(10/13/10, CJ, land manager)

Occasionally, somebody will say, “Here's an applicator for herbicide that works better than anything I've used." And I'll try it, and that is better. (10/28/10, RI, land manager)

Additionally, new sources of funding can open up possibilities for restoration activities that would not have otherwise been considered. One respondent describes funding as creating "a shot gun effect" in which they focus on specific sites that are receiving funding $(8 / 25 / 10, \mathrm{RS} 2$, volunteer coordinator). New information could thus be scientifically, politically, or financially driven.
Entrenchment and dissent

In collective decision-making processes, group discussion and even dissent fosters new ideas, truthfulness, and solidarity (Dryzek and List 2003, Hopthrow and Hulbert 2005, Argyres and Mui 2007, Mulford et al. 2008, Landier et al. 2009). Sometimes, however, individuals can be willfully and strongly tied to their own position, thus becoming entrenched (Anderson et al. 1980, Anderson and Lindsay 1998, Meyer et al. 2000, Locke et al. 2008, Dane 2010). For example, one respondent said of restoration:

It's not an exact science. So a lot of people have a lot of different opinions about things. Most of the people that I've dealt with, who are in those roles as heads of [omitted], they're all very strong-willed individuals. And they all have their idea of what's right and what's wrong. That's what's so ironic about it is they'll argue back and forth but they're really trying to get to the same point. [They have] ideals or theories that they stick to and they won't budge. And for whatever reason, maybe it's just the individuals involved that they don't like each other or whatever. But they just dig their heels in and it just seems silly.

(12/22/10, LB4, land manager)

Dissenters must decide to either conform or remain entrenched in their view. Dissent may be sustained or increased when a dissenter thinks the decision maker is going to choose an option that the dissenter does not agree with (Che and Kartik 2009). Dissent can also be supported by the decision maker when he/she thinks that the choice he/she makes is going to result in subpar effort on the part of the dissenter (Landier et al. 2009). Eventually, there is pressure among members of a group to come to an agreement so that progress can be made toward goal achievement (Che and Kartik 2009, Landier et al. 2009). There may be social, psychological, or professional costs to diverging from the opinions of others in the group. Thus, a person with a firmly held belief may eventually "give in," and change his/her position to one that is closer to the rest of the group. One respondent explained the cost of dissent as:

We have to pick our battles carefully. And decide what is worth falling on a sword over and what isn't. This is a fast-paced place and decisions aren't revisited a lot. So as employees who like to wake up every morning and have a job to come to, we need to be careful that we just don't second guess every decision that gets made around here that we just don't agree with because you're not very popular with management when you do that.

(01/10/11, JA3, land manager)

Our observations indicate that there is no clear link between dissent and entrenchment; the presence or absence of each 
mechanism varies with individuals and issues. For example, someone could dissent, but not be entrenched in their opinion and quickly converge towards the collective position. Similarly, someone could be very entrenched in his or her position, which may coincide with the general opinion, not caring if the collective opinion stays or moves away from that position.

\section{Decision strategies}

Participants' values or positions are often conceptualized as converging towards the same position through deliberation (Arrow et al. 2000, Regan et al. 2006). We recognize both shared consensus, where all group members participate in the decision process and converge towards a decision, and unshared consensus, where one or several dominant group members make the final decision (Conradt and Roper 2009). In the latter case, there may be an advisory process where group members discuss an item, but one or a few point persons make the actual decision (Sniezek 1992, Sniezek and Buckley 1995, Budescu and Rantilla 2000). One point person referred to it as having to "flex our muscle" over advisors when consensus is not reached. In the instance of a contentious decision, higher levels of management might step in and make a decision as outside arbiters. For example:

And if I'm not feeling like I can be heard the way I
think I need to be heard, then you can keep taking it
up the step. Next would be LF. And GJ3. Once it's at
the vice-president level, if there's a difference of
philosophy, that's where it gets resolved. And RR2,
our [boss] will either listen and let the VPs
deliberate. Or [RR2] will make a decision if s/he
feels that a decision needs to be made if there's
disagreement at the end.
(01/10/11, JA3, land manager)

Research questions and working assumptions

Based on the literature and ethnographic observations above, we focus our modeling work on the decision-making process of groups already at the table and involved in ecological restoration, i.e., we assume that group structure will not break down as its members work towards agreement on how to address a common goal. Specifically, in the base model we are interested in: the mechanisms of group interaction, which include structural components such as the number of people; the number of groups; and the types of interactions within and across these groups. We are also interested in the characteristics of social standing (status, or respect), and the influence of new information and cases in which participants have vastly different positions for a decision (position polarization). The complex model also incorporates psychological dimensions of decision making, characterized as position entrenchment and the cost of dissent. We use our models to examine how group structure and composition, interaction types, and psychological dimensions affect: (1) participants' collective position for a decision, (2) the distribution of positions, and (3) the occurrence of different decision strategies.

\section{THE MODEL}

Building on prior work (Regan et al. 2006) and the modeling design guidelines above, we implemented a stylized model of collective decision making in Netlogo (Wilensky 1999), an agent-based modeling software. Current knowledge about Chicago Wilderness organizations' decision-making processes supported model parameterization and the design of meaningful scenarios. We were not seeking to model any particular organization or how any particular decision is reached, but rather to provide a general framework that can explain collective decision-making in a variety of ecological restoration cases. As explained above, we focus on collective decision making that concerns on-the-ground management decisions (e.g., how much to burn), once the policy decision (e.g., whether to burn or not) has already been made. The base model includes heterogeneous actors, defined group structures, and a variety of ways in which agents interact with and adapt to each other (Fig. 3). Simulations with this base version focused on the effects of structural characteristics and explained the convergence process. However, the base model did not produce the variety of position trajectories and final decision outcomes that is indicated by our ethnographic observation. Thus, we designed a more complex version of the model, adding behavioral components (Fig. 3) to explain the variety in dynamics and outcomes.

\section{Agents}

Both the base and complex models simulate interactions of a medium-large organization with 18 total agents. This number is the average size of the organizations we studied and a number that can be evenly divided into two or three groups, the latter being the maximum number we observed in Chicago Wilderness organizations. This setup allows us to isolate the effect of number of groups from the effect of group size. We do not make assumptions about outcomes for organizations with more than three groups or a larger number of participants. Each group is assigned one point person with final decisionmaking authority and who represents the group to others. All other agents are classified as advisors and are assigned to one of the groups headed by a point person.

Agents have positions about management actions (e.g., invasive species removal or prescribed burning). Agent position $p$ ranges between 0 and 1 , is continuous, and represents an agent's opinion about the magnitude of effort for a specific management action. As noted in the model design guidelines above, our observations suggest that positions correspond to support for a specific magnitude of an action that has already been established as a policy in the organization, rather than a dichotomous decision of either 0 
Fig. 3. Order of events in the model. (Base version in black, complex version in blue.)

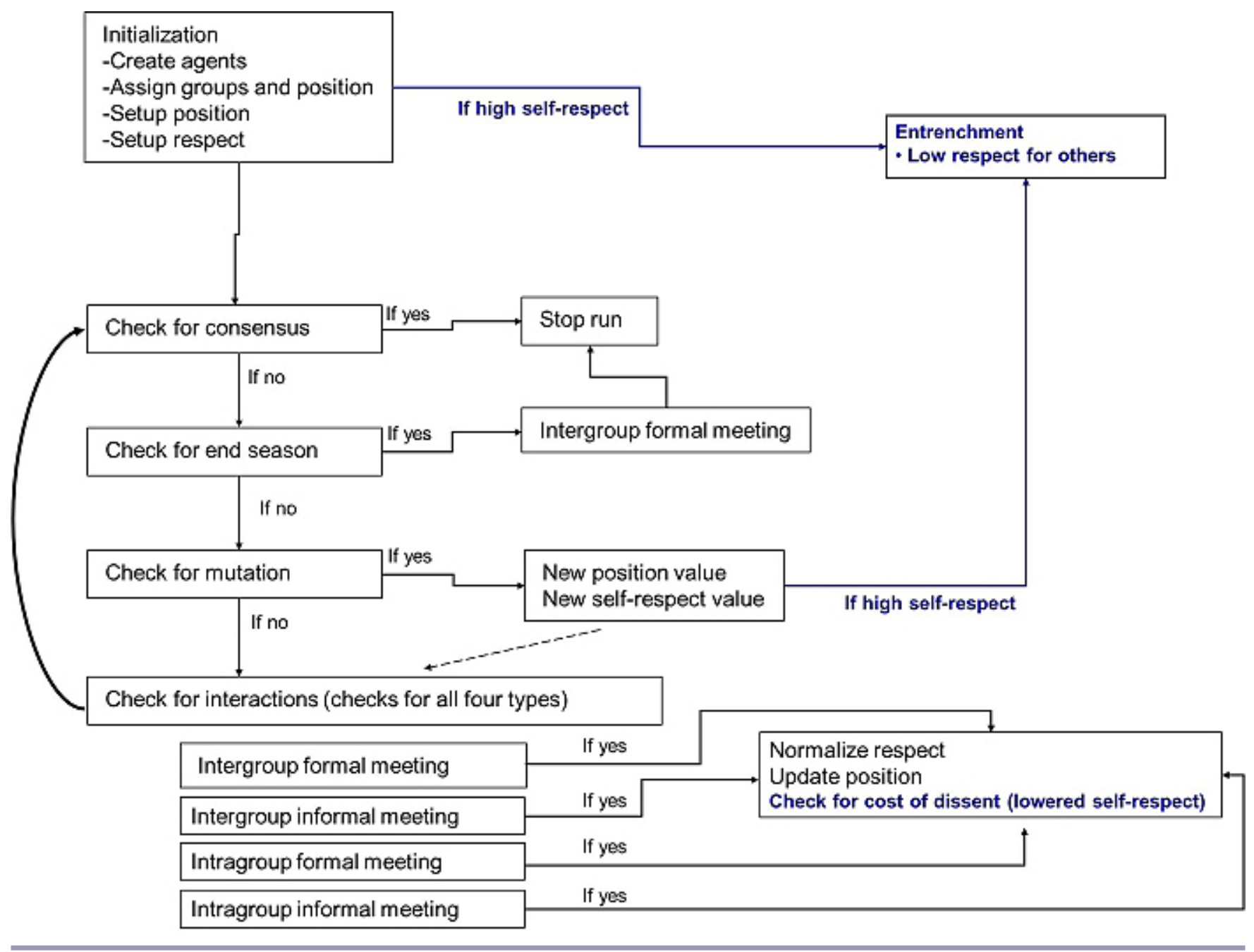

or 1. For example, for a decision to remove an invasive shrub population in a 2-ha area, a position of 0 in our model represents the opinion that no removal should take place, while a value of 0.8 represents the opinion that $80 \%$ of the shrub population should be removed.

Agents also have respect values $r$ for their own position and for that of other agents with regard only to the one decision being modeled, ranging between 0 (no respect) and 1 (highest respect). Respect represents how much the agent values a particular position of an agent (including themselves) due to either agent expertise or agent effort within the group, as supported by our observations and the literature (Harvey et al. 2000, Yaniv and Kleinberger 2000, Regan et al. 2006). In our model, respect is independent of psychological issues like selfconfidence, self-worth, or trust in oneself or others. It is a measure of how much the actor supports a source of information for the particular issue being decided.

\section{Events within a run}

The model is first initialized with the creation of up to 18 agents who will form one group, or who will be evenly split into two or three groups and assigned randomly to each. Each agent is assigned a position and respect value for its own position, as well as respect values for the position of other agents, drawn from random, uniform distributions (Table 1).

Each iteration or time step in the model represents one workday. Restorationists construct their management schedules on a seasonal basis due to the seasonal constraints inherent in their practice, much like in farming. Therefore, the model assumes a planning period of three months (one season $=$ one run of 64 workdays), unless the group reaches agreement first (Table 1). 
Table 1. Default parameter values for base model scenarios.

\begin{tabular}{lc}
\hline \hline Parameter & Value \\
\hline Length of simulations (workdays) & 64 \\
Agents (no.) & 18 \\
Groups (no.) & 1 \\
& 2, equal-sized \\
& 3 , equal-sized \\
Position values & Between 0 and 1, random uniform \\
& distribution \\
Respect values & Between 0 and 1, random uniform \\
& distribution \\
Formal meeting frequency (days) & 20 \\
Probability of informal intragroup & 100 \\
interaction (\%o) & 20 \\
Probability of informal intergroup & \\
interaction (\%o) & 0 \\
Mutation rate (\%o) & \\
\hline
\end{tabular}

In the base model, each time step involves two main events: mutations (the influx of new information), and interactions (both formal and informal deliberations). In the complex version of the model, two additional mechanisms are activated: entrenchment (agents' strongly held position that reduces the influence from others), and cost of dissent (the internalized pressure an agent feels to conform to the group as the decision-making period ends) (Fig. 3). At the end of each run, one of three decision strategies occurs. Details of all events are described below.

\section{Mutations}

Mutations represent external influences that change the position of targeted agents, as supported by the literature and Chicago Wilderness observations. Both the selection of agents for mutation and their change of position are random because data on the occurrence of mutations is not readily available; random is the simplest unbiased assumption for the frequency and direction of this mechanism. A mutation is thus equally likely to result in a substantial or in a minimal change in position. At every time step, each agent may undergo a position mutation at a probability of either 5 per mil or 10 per mil, which means an average of 6 and 12 mutations in a season, respectively. We chose these probabilities because, while we do not know exactly how often mutations occur, we know that they do occur, but at low frequencies within the Chicago Wilderness organizations we observed. Our sensitivity analysis showed that probabilities of 5 per mil ensured that at least a few substantial mutations occurred in a run, while probabilities above 10 per mil resulted in overly erratic decision-making processes that did not match our observations of these organizations. If an agent undergoes a mutation, it also receives a new random value for its own position to represent the agent's support for the new information in light of the agent's own expertise to evaluate it. A random change of respect allows us to match our observations (see modeling design guidelines); actors may place more or less value on a new procedure, technique, or source of funding, depending on the new information they possess. Through interactions with other agents, a mutation can influence the collective position outcome.

\section{Interactions and position updating}

Previous models assume that all agents interact with all other agents in each time step (Regan et al. 2006). Instead, agents in our model interact with a subset of other agents, depending on the type of interaction, and only at the time they are selected to participate in that interaction. Based on our observations of the Chicago Wilderness organizations, we model four basic types of interactions: (1) formal intergroup interactions at regular intervals involving the point persons among two or three groups within an organization (Fig. 2a); (2) formal intragroup interactions at regular intervals of all the advisors and the point person in a single group (Fig. 2b); (3) informal intergroup interactions involving agents from at least two different groups (Fig. 2c); (4) informal intragroup interactions, where only agents in the same group spontaneously interact (Fig. 2d). Types 1 and 3 do not occur when agents form only one group.

To establish reasonable estimates of the frequency of each meeting type, we derived values from our interviews and observations. For informal meetings, the model generates a random number for each agent to determine if it might interact. If two or more agents are flagged, the interaction occurs. Information from our interviews suggest that informal intergroup interactions occur about once a week, or $20 \%$ of the time, and that informal intragroup interactions occur every day, or $100 \%$ of the time. To achieve these total interaction probabilities for an organization with two groups and 18 agents, each agent is given a fixed interaction probability of $2.22 \%$ and $11.11 \%$ for intergroup and intragroup information interactions, respectively. We also extend these percentages to scenarios with three groups to make the results comparable. For three groups, however, the use of fixed probabilities per agent results in a slightly lower chance of intragroup interaction (it is less likely that two agents selected will be in the same group when groups are smaller), and in a slightly higher chance of intergroup interactions (it is more likely that two agents selected will be in different groups when there are more groups). Formal meetings occur at intervals of one month (equivalent to 20 time steps denoting a monthly staff meeting), including the first simulated day of the run. We conducted sensitivity tests that showed that higher values of meeting frequency led to faster convergence than suggested by our interviews, while lower values did not accurately represent the frequency of convergence in the Chicago Wilderness organizations observed.

Over the course of a planning season (a run), agents interact and positions change based on the level of respect agents have 
for each other's position. First, the respect values that agents have for themselves and for all the other agents involved in a specific interaction are normalized to ensure relative weighting is only applied across the values of agents involved in the interaction, and not across all the agents in the organization. Consistent with prior models of consensus (Davis et al. 1993, Davis 1996, Kerr and Tindale 2004, Regan et al. 2006, Ekel et al. 2008), each agent's position value is then updated by calculating an average of the positions of all interacting agents, weighted by the respect that each agent has for each other, as follows:

$$
P_{i, t+1}=\sum_{j=1}^{n} r_{i j} \times P_{j, t}
$$

where:

$p_{i, t+1}=$ updated position of agent $i$ after the current interaction;

$n=$ total number of agents involved in current interaction;

$r_{i, j}=$ respect that agent $i$ has for agent $j$ (including itself), normalized among the $n$ interacting agents; and

$p_{j, t}=$ current position of agent $j$.

\section{Entrenchment}

In the complex version of our model, entrenchment occurs when an agent is assigned a respect value for its own position of 0.9 or higher. In this case, the entrenched agent will lower its respect for all other agents to 0.01 . We use 0.01 because we consider 0 to be unrealistic. If respect for others were 0 , the entrenched person would not consider anyone's opinion at all, so their position would never change. Instead, we assume that entrenched agents will still engage with other agents, even if they value others' opinions much less than their own. If an agent's respect value for its own position is lower than 0.9, the agent is not entrenched and respect values for others are randomly assigned. Entrenchment can also occur during the course of a run if a new respect value for its own position due to mutation (described above) is above 0.9. A 10 per mil probability of mutation resulted in at least one agent per run becoming entrenched after mutating (1.2 times per run on average), which is a reasonable portrayal of entrenchment as a regular mechanism based on our empirical observations.

\section{Cost of dissent}

In the complex model, during the last month of the season (starting at Time Step 44 and only after an interaction has taken place) agents examine how different their position is from the average position of the other agents with which they interact. If the difference between an agent's position is greater than the standard deviation of the positions of the agents with which it interacts, then cost of dissent is activated for the first agent. The cost of dissent mechanism involves reducing the agent's respect value for its own position, which will thus increase the influence of other agents in future interactions. As a result, the dissenting agent will be more likely to converge towards the rest of the group the next time it interacts.
The effect of cost of dissent on respect for the agent's own position differs depending on the role of the agent. Interviews suggest that, as leaders, point persons are less prone to changing their positions, and therefore are less susceptible to cost of dissent. Advisors, however, more acutely feel pressure to conform and are more susceptible to cost of dissent. Each day after Time Step 44 (when the cost of dissent period starts), the agent's respect for its own position will decrease by their respective amount ( 0.2 for point persons or 1.0 for advisors) multiplied by $t_{c} / 20$, where $t_{c}$ equals the number of days spent in the cost of dissent period. Therefore, respect for the agent's own position is more greatly reduced with each passing day, reflecting the pressure to conform as the season draws to an end. On average, there were 13 instances per run when agents reduced their respect for their own position due to cost of dissent.

\section{Decision strategies}

At the end of each run in both model versions, there are three alternative decision strategies from the decision process. First, whole-group convergence occurs when all of the position values are within 0.01 of each other, and the simulation ends. Second, if there is no whole-group convergence, the decision will be made by the group point persons. Point persons have a formal intergroup interaction representing discussion and compromise, and if their position values are within a range of 0.2 of each other, the decision is the average of the point persons' position values (point-person consensus). Third, if the difference in position values between the point persons is greater than 0.2 , the decision is assumed to be made by a higher authority such as by a department director or an executive board, whereby a decision maker randomly chooses one of the positions held by the point persons (outside arbiter decision). By definition, if there is only one group, there is only one point person and the decision is never determined by an outside arbiter. The model thus establishes explicit mechanisms that link the position of each individual in the organization with the final decision, whether it is reached through convergence or not.

The choice of the above thresholds is based on interviews and observations in the Chicago Wilderness organizations. Our data analysis suggested that whole-group convergence does occur, but is very rare in Chicago Wilderness. Similarly, outside arbiter decisions are also rare in Chicago Wilderness, but there have been instances where such interventions were needed. Point-person consensus is the most frequent form of decision strategy observed and recorded. We tested our model with several values for these thresholds to determine the ones that would recreate frequencies similar to the ones observed. A value of 0.01 for whole-group convergence produced rare occasions of overall consensus similar to our observations, while a value of 0.2 among point persons ensured that most of the decisions would not require outside arbiter interventions. 


\section{SIMULATION EXPERIMENTS AND RESULTS}

\section{Base model simulations}

We conducted a series of stylized tests using settings (scenarios) derived from the ethnographic interviews and observations. Default parameter values for all scenarios are shown in Table 1. We ran each scenario 30 times and used three metrics to assess the outcomes of each scenario: the 30run average collective position (a measure of the final position value), the 30-run average spread of individual positions (a measure of the degree of convergence around the final position value), and the frequency of decision strategies over 30 runs (a measure of the likelihood of whole-group convergence versus point-person consensus or outside arbiter decisions) (Table 2).

Table 2. Output variables (V) and their associated metrics (m).

\begin{tabular}{ll}
\hline \hline V1. Collective position & $\begin{array}{l}\text { Average position of agents at the } \\
\text { end of each run. }\end{array}$ \\
\hline m1. Average collective position & $\begin{array}{l}\text { Average collective positions across } \\
30 \text { runs. }\end{array}$ \\
V2. Spread of individual positions & $\begin{array}{l}\text { Standard deviation of agent } \\
\text { positions from the mean (collective } \\
\text { position) at the end of each run. } \\
\text { Average standard deviation of } \\
\text { positions }\end{array}$ \\
V3. Decision strategy & $\begin{array}{l}\text { agent positions from the mean } \\
\text { (collective position) across } 30 \text { runs. }\end{array}$ \\
& $\begin{array}{l}\text { One of three types of decision } \\
\text { strategies occurring at the end of } \\
\text { each run: whole-group } \\
\text { convergence; point-person } \\
\text { consensus; outside arbiter. }\end{array}$ \\
& $\begin{array}{l}\text { Proportion of each of type of } \\
\text { decision strategy across } 30 \text { runs. }\end{array}$ \\
\hline
\end{tabular}

\section{Effect of number of agents and number of groups}

To examine the effect of the number of agents and number of groups on decision making, we ran the base model with one, two, and three groups, and with all of the possible numbers of agents ranging from three to 18 . Because positions are randomly assigned between 0 and 1 , the average position at the beginning of all runs was 0.5 . It was no surprise then that the final average position converged towards 0.5 in all scenarios (Fig. 4a). In fact, average collective position did not change significantly in any of the subsequent scenarios we tested with the base model because of this initial average position (although not random, polarized scenarios also start with a collective position of 0.5 ). Because this metric did not allow us to distinguish effects across scenarios in the base model, we focused instead on measures of position variation (spread of individual positions) and decision strategies.

The average spread of individual positions increased as both the number of agents and the number of groups increased (Fig. 4b). With one group, the spread remains consistently low. Spread of positions was not influenced by the number of agents because convergence was easier to reach within one group than across groups, regardless of the number of agents. With several groups, the likelihood that whole-group convergence occurred decreased because intragroup interactions are more likely to occur than intergroup interactions. This resulted in intragroup convergence but also in intergroup divergence.

The greater divergence obtained with multiple groups translates into the need for point persons to negotiate, or for outside intervention so that a final decision can be made. With one group, nearly all of the simulations ended with wholegroup convergence (Fig. 4c), whereas with two and three groups, the decision strategies were nearly always pointperson consensus (Fig. 4d and 4e). Essentially, our model shows how having multiple groups creates an institutional barrier to whole group interaction and convergence, reproducing observations in our cases and in the literature (Argyres and Mui 2007, Taylor and Short 2009).

\section{Effect of interaction type}

To examine the effect of interaction type (Fig. 2), we ran the base model with five scenarios with both two and three groups:

- Scenario 1: intragroup informal meetings only

- Scenario 2: intragroup informal meetings + intragroup formal meetings

- Scenario 3: intragroup informal meetings + intergroup informal meetings

- Scenario 4: intragroup informal meetings + intragroup formal meetings + intergroup informal meetings

- Scenario 5: intragroup informal meetings + intragroup formal meetings + intergroup informal meetings + intergroup formal meetings

When formal meetings were included in the model (Scenarios 2,4 , and 5), the average spread of individual positions showed a decreasing trend (Fig. 5a). Intragroup formal meetings (Scenario 2) showed a greater decrease in spread than when intergroup informal meetings were included (Scenarios 3 and 4) because in the former, all agents within a group intervene in the interaction and all their positions are updated simultaneously. Intergroup informal meetings, on the other hand, occur far less frequently and among fewer agents. Intergroup meetings promote greater convergence when they are formal (Scenario 5) because such meetings bring point persons together on a regular basis. When all four interaction types occur (Scenario 5), the spread of individual positions is the lowest and convergence is more likely.

Point-person consensus was the resulting decision strategy at least $93 \%$ of the time in any scenario (Fig. 5b), which is consistent with our observations of Chicago Wilderness organizations. The only two instances of whole-group 
Fig. 4. Effect of number of agents and number of groups on: (a) collective position, (b) spread of individual positions, and frequency of decision strategies with (c) one, (d) two, and (e) three groups. Error bars are + 1 SD.
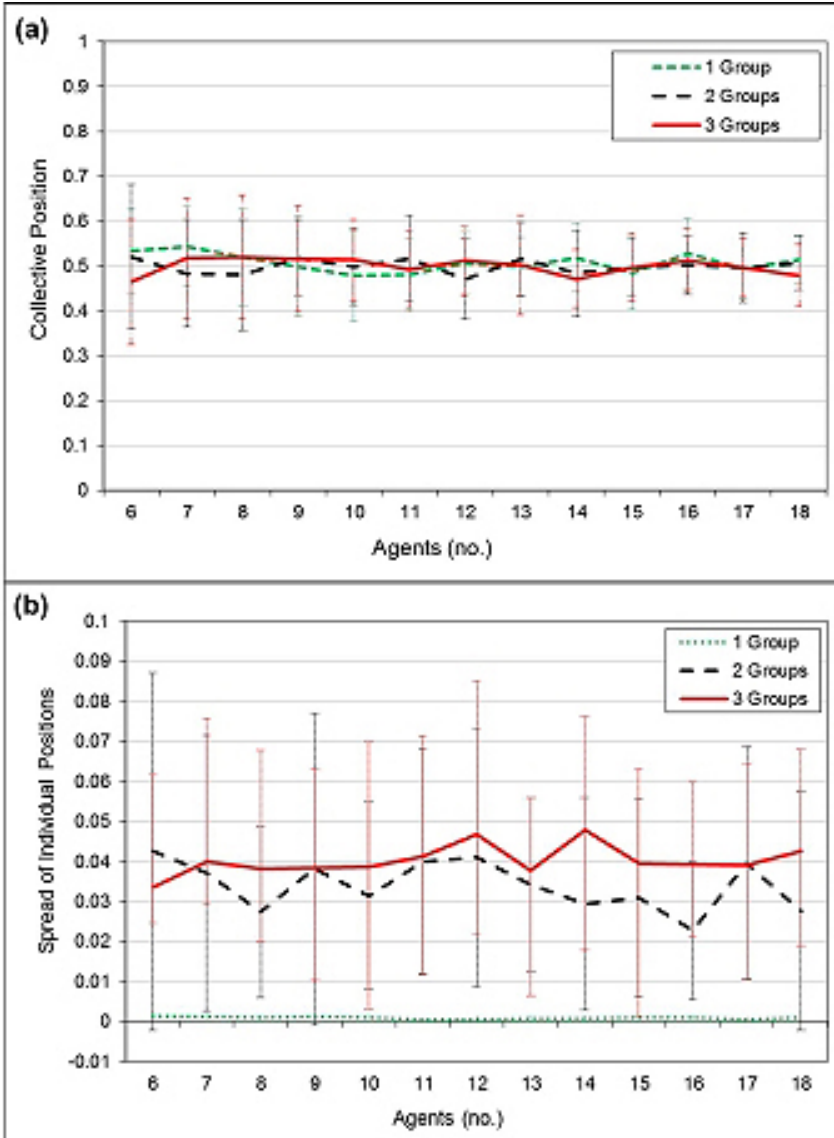

convergence occurred under Scenarios 2 and 4 with two groups and intragroup formal meetings, which promote convergence. Outside-arbiter decisions occurred under Scenarios 1, 2, and 3. Scenarios 1 and 3 exclude intragroup formal meetings, the strongest mechanism promoting convergence. While this mechanism was present in Scenario 2, the occurrence of an outside arbiter with three groups can be explained by the higher number of groups, which increases the likelihood of divergence across groups, and thus the need for outside intervention.

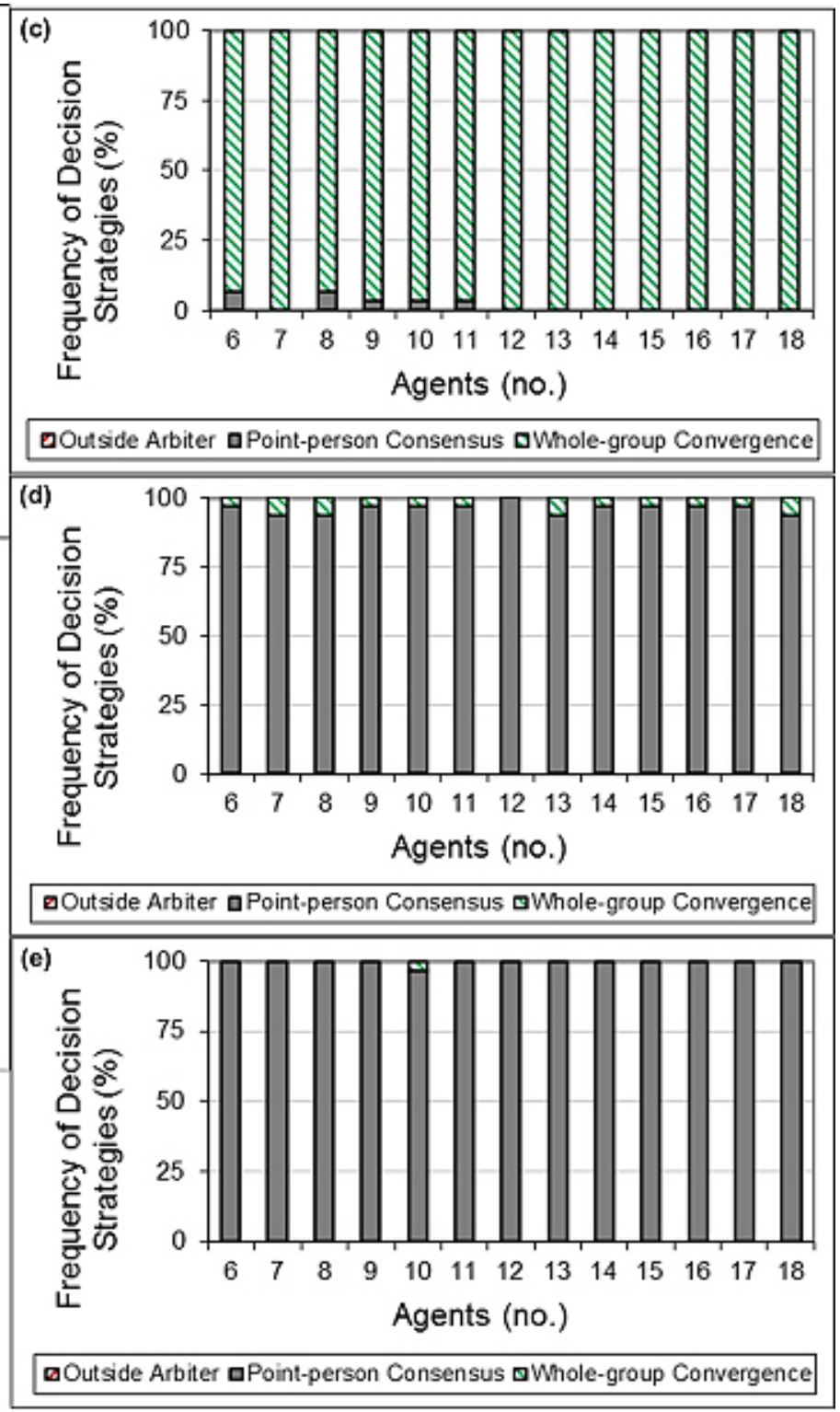

Fig. 6 shows the influence of the various types of meetings in the process towards convergence, or lack thereof. Note that in sample runs without formal meetings (Fig. 6a and 6c) the spread of individual positions decreases gradually. In contrast, runs with formal meetings (Fig. 6b, 6d, and 6e) show that the first formal meeting facilitates a dramatic reduction in position spread, and subsequent formal meetings reinforce this reduction, producing a step-like convergence. 
Fig. 5. Effect of interaction types on: (a) the spread of individual positions, and (b) frequency of decision strategies. Error bars are $+1 \mathrm{SD}$.

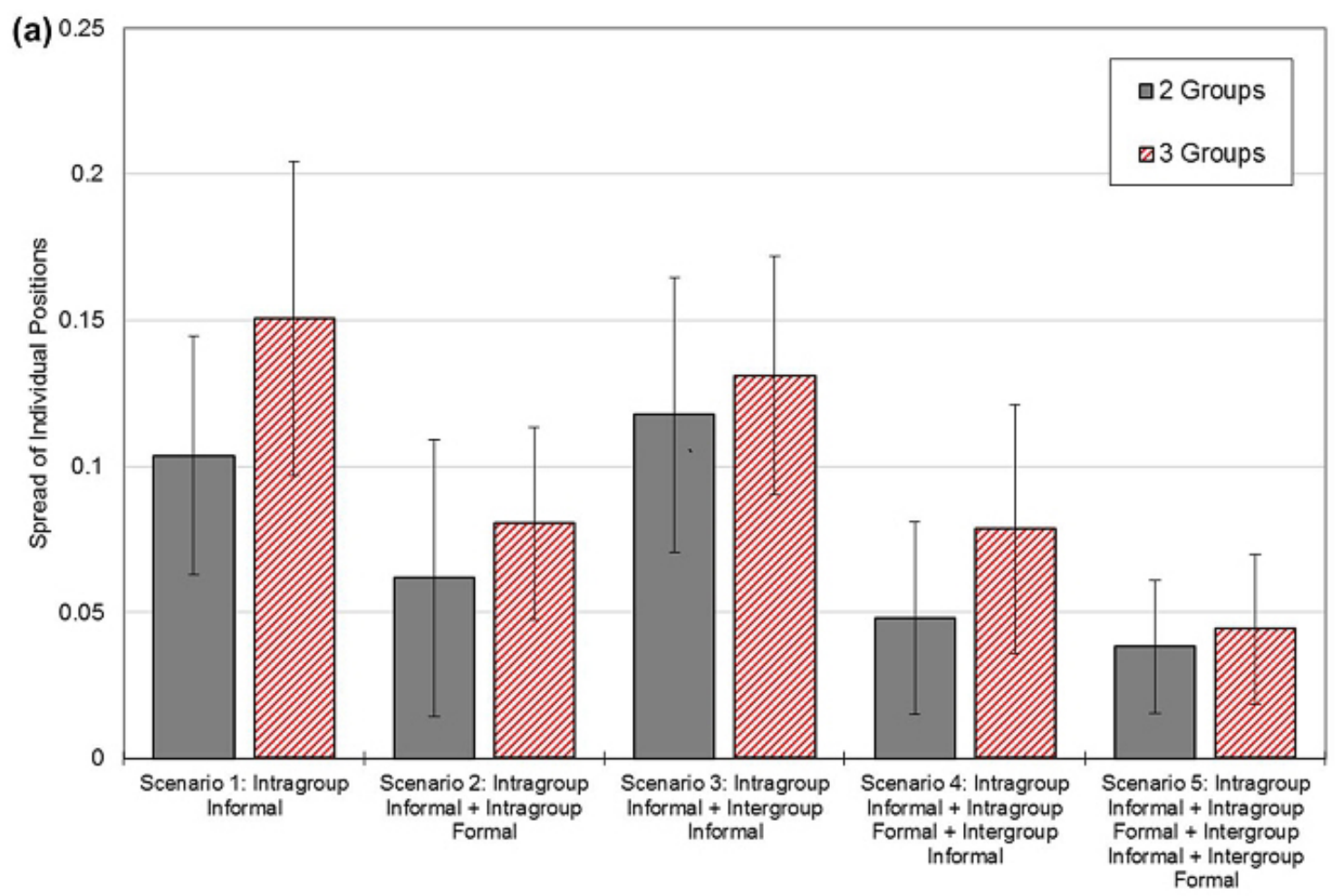

(b)

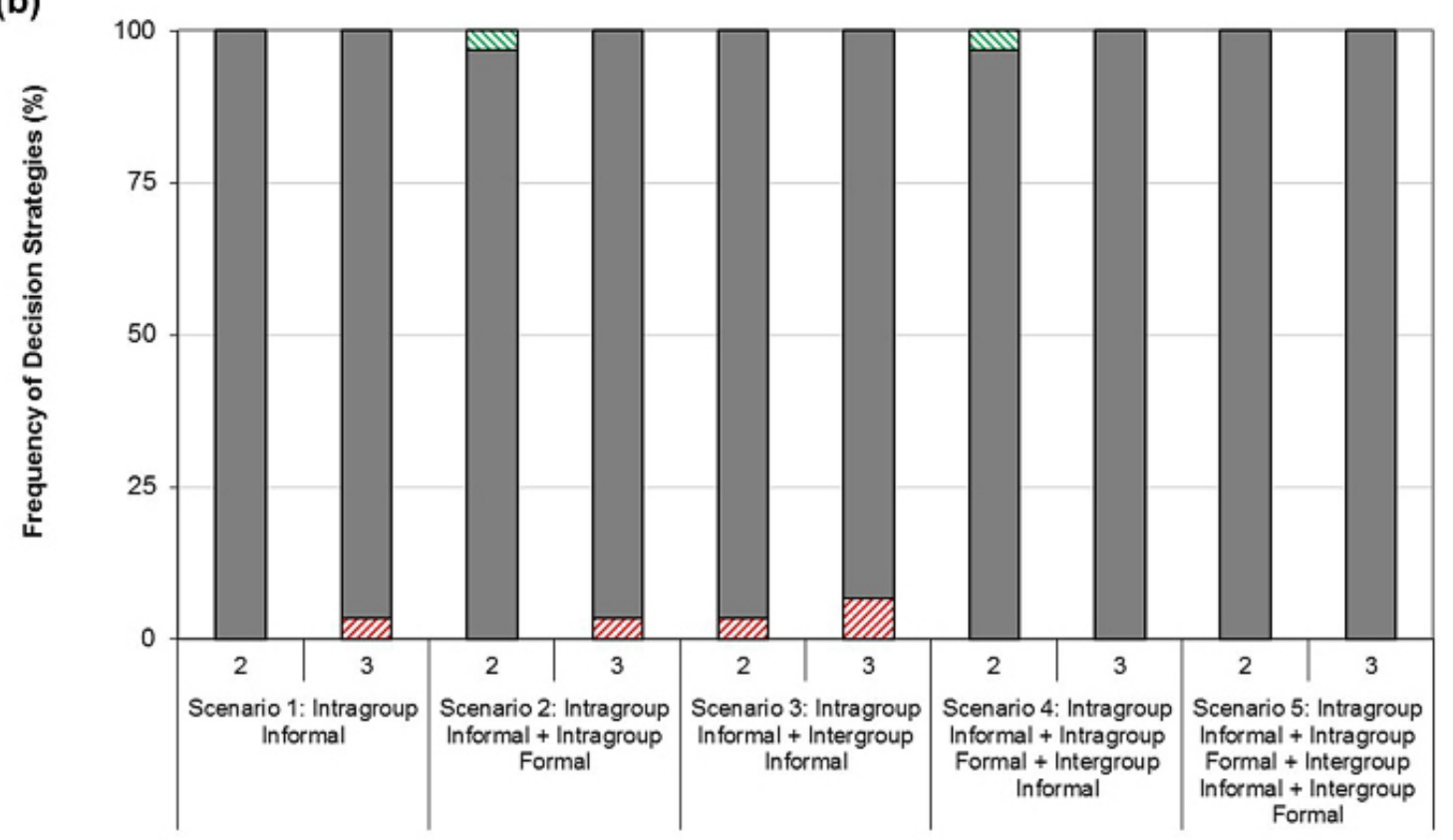

घOutside Arbiter aPoint-person Consensus घWhole-group Convergence 
Fig. 6. Evolution of individual positions in two groups across interaction type scenarios: (a) Scenario 1, (b) Scenario 2, (c) Scenario 3, (d) Scenario 4, and (e) Scenario 5. Yellow arrows indicate intergroup interactions and purple arrows indicate intragroup interactions. Solid arrows show formal interactions and dashed arrows show informal interactions. (Note: only a few examples of informal meetings are indicated.)
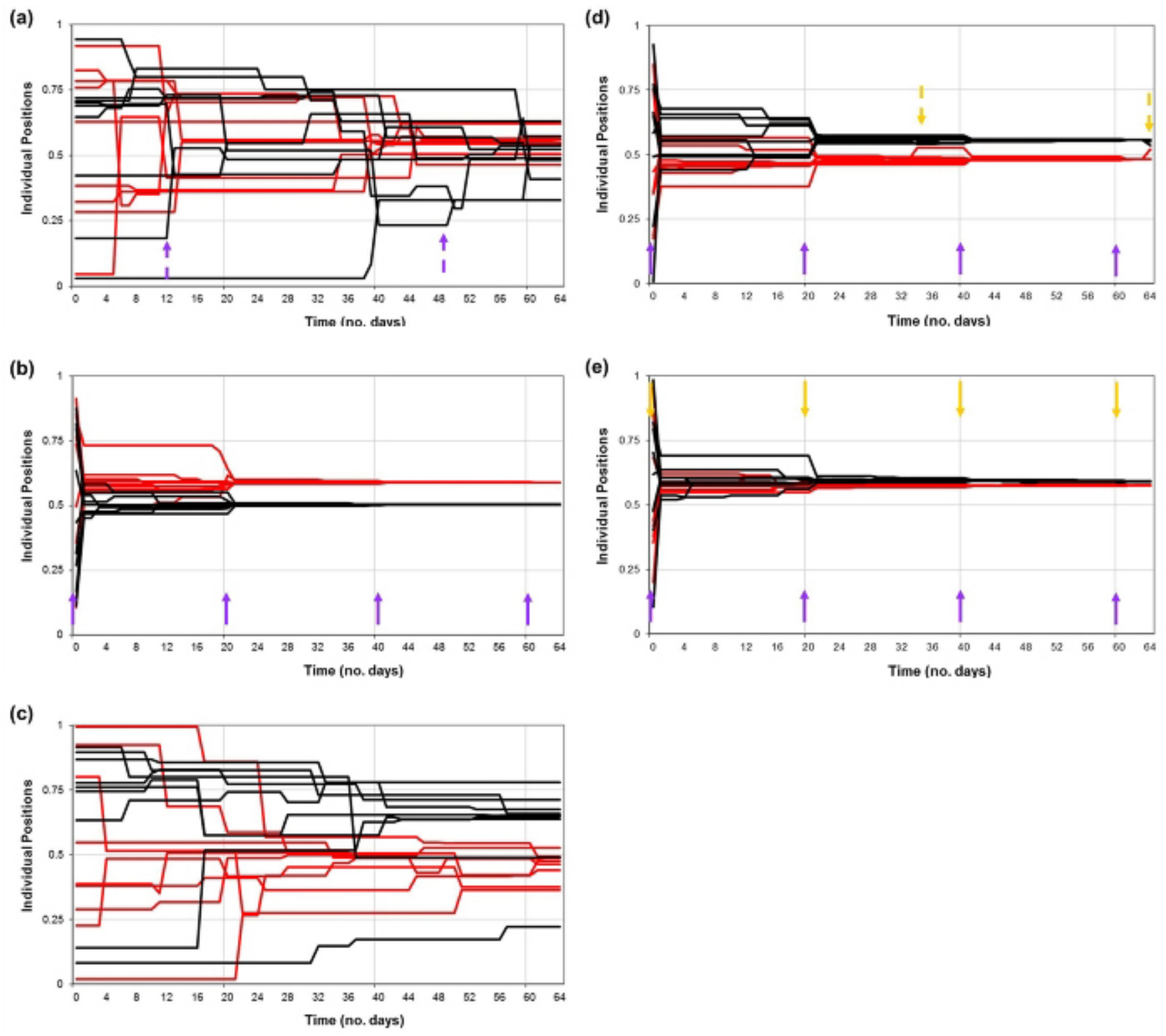

\section{Effect of mutation}

Mutation causes deviations in position values throughout a run, thus increasing the spread of individual position (Fig. 7a). There was little difference in the effect of mutation between probabilities of 5 per mil and 10 per mil, however. The effect of mutation compounds the trend towards divergence introduced by a larger number of groups.

Mutation produced the greatest change in decision strategy with one group. Without mutation, whole-group convergence occurred $100 \%$ of the time (Fig. 7b). With a mutation rate of 5 per mil, point-person consensus occurred $60 \%$ of the time and whole-group convergence occurred $40 \%$ of the time. A rate of 10 per mil drastically favored point-person consensus ( $87 \%$ of runs), with only $13 \%$ of the runs resulting in whole- 
group convergence. When individuals are organized in one group, whole-group convergence is easier to attain than when two or three groups are present. Adding mutation, even at low rates, causes the spread of positions to pass the low threshold for whole-group consensus and immediately switch to pointperson consensus as the dominant decision strategy. When modeled with two or three groups, point-person consensus was already the outcome in nearly all cases, regardless of the mutation rate. The positions spread among point persons surpassed the threshold that activated outside interventions infrequently and only with three groups and a 10 per mil mutation rate. Despite mutations, intergroup and intragroup formal meetings are effective at driving positions back toward the mean of each group, resulting in point-person consensus.

Fig. 7. Effect of mutation probability on: (a) the spread of individual positions and (b) decision strategies. Error bars are +1 SD.

(a)
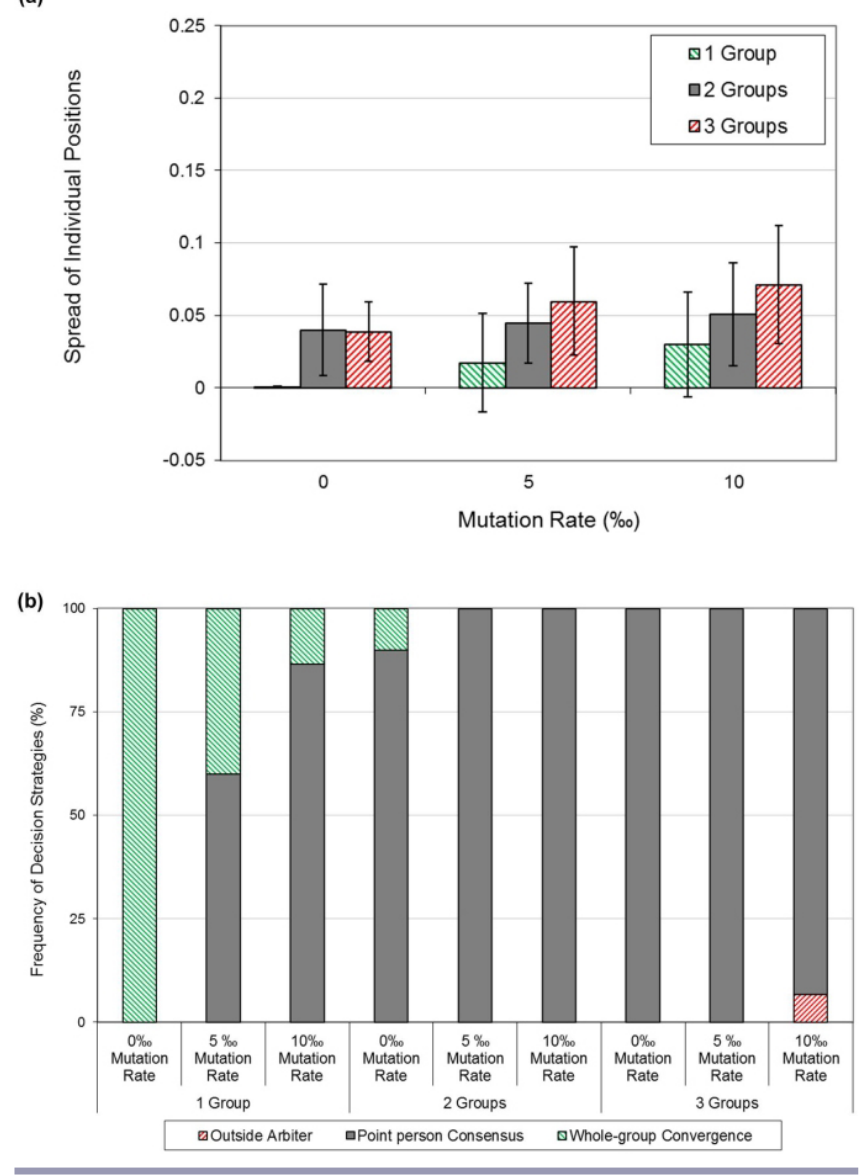

Effect of polarized position distribution

We ran additional scenarios whereby initial positions are polarized, to reflect a situation where agents vary greatly in their expertise or opinion about a decision outcome. The setup included:
- Intragroup polarization within one, two, or three groups, where half the agents in each group had positions of 1 and the other had positions of 0 .

- Intergroup polarization between two groups, where agents in one group had positions of 1 , and agents in the other group had positions of 0 .

Because the final collective position was not affected by polarization, we focus here on the other two metrics: average spread of individual positions and frequency of decision strategies. Based on the ethnographic data, we used a mutation value of 10 per mil.

With intragroup position polarization, there are many opportunities for interaction and convergence, particularly through intragroup formal meetings, so that the average spread of individual positions or frequency of decision strategies are not affected as much, relative to the results without polarization (Fig. 8a and 8b).

Intergroup position polarization, on the other hand, led to a noticeable increase in the average spread of individual positions when compared to results without polarization (from 0.05 to 0.15 ). Point-person consensus occurred $93 \%$ of the time and outside arbiter occurred $7 \%$ of the time. The reduced opportunities for interactions between groups helps maintain the divergence (Fig. 8c), and increases the need for pointperson negotiation and outside intervention.

\section{Base model conclusions and limitations}

The base model provides several insights into the decisionmaking process. Formal intragroup meetings and point persons facilitate convergence when other counteracting forces are in place, such as the presence of multiple groups, mutation, and polarization. While the base model did recreate some differences in position spread and decision strategies across scenarios, it did not generate the variety of trajectories that is often observed in group decision making. In the base model, all of the agents come together fairly quickly around a common value (0.5). Ethnographic observations, however, suggest that the trajectory of collective position within any given run is more varied. The mechanisms of the base model were not enough to reflect the presence of debate, contention, and negotiation that typically occurs in these organizations, for example:

I think the most obvious example there would be if they wish to not burn a particular [area within a] site and not want to get fire in there, that's going to be tough. Because I wanna manage these sites to improve them. And that's where I want to get that fire in, but then, at the same time, the research is saying, well . . . the research end of things would say, 'Well, we're gonna inform how to manage.' So 
Fig. 8. Evolution of individual positions in two groups across polarization scenarios with a $10 \%$ mutation rate: (a) no polarization, (b) intragroup polarization, and (c) intergroup polarization. Purple circles show examples of mutation. Yellow arrows indicate intergroup interactions and purple arrows indicate intragroup interactions. Solid arrows show formal interactions and dashed arrows show informal interactions. (Note: only some meetings are indicated.)
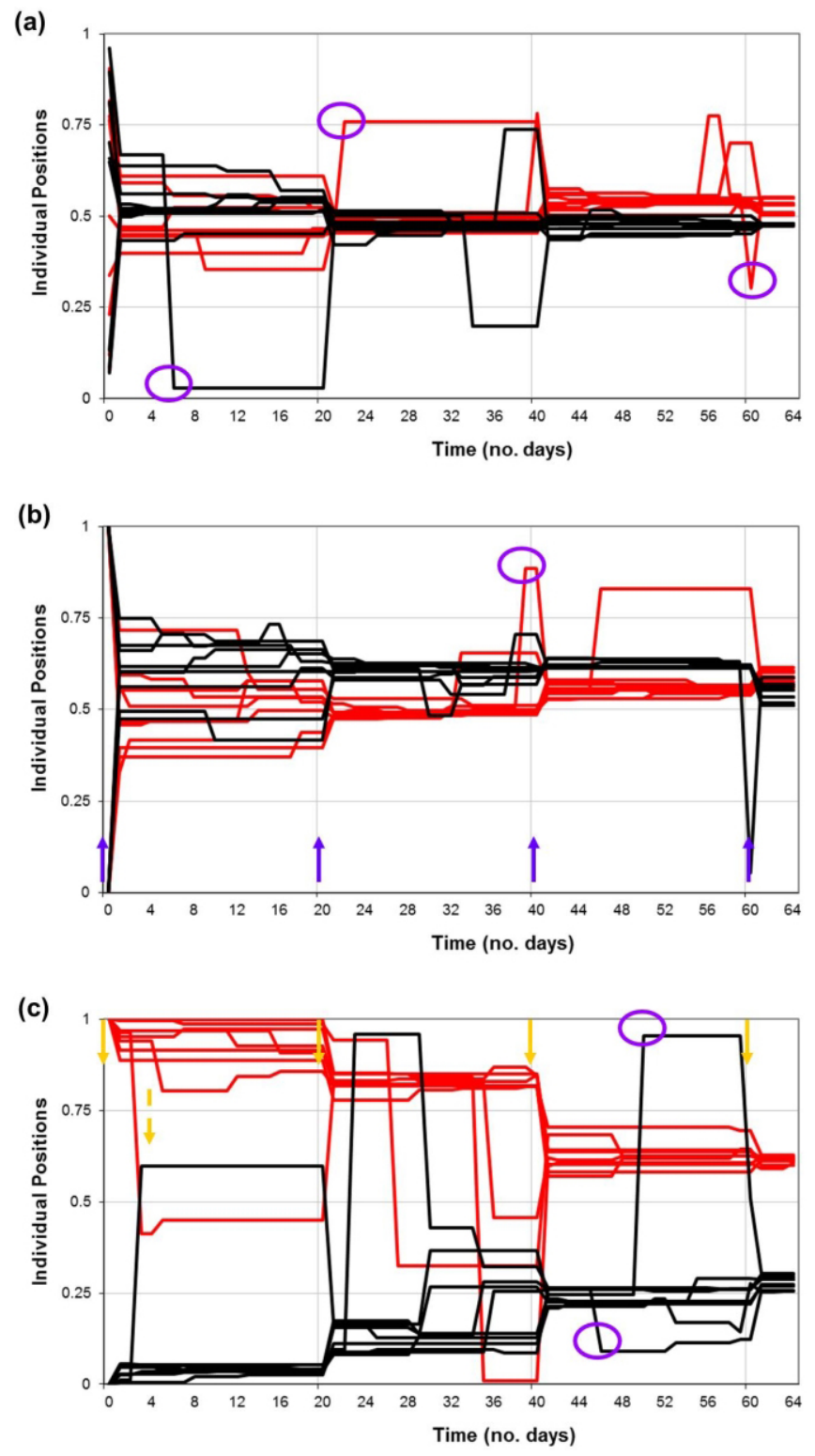

we have to kind of step back from this burning to learn how these processes work.... [It gets resolved] through conversations if each person in that conversation would state their case, then we would just work that out.

(10/13/10, CJ, land manager)

I think we need to move, to go through actually start removing maple trees to get more sunlight in there, to dry the area out, to get more herbaceous recovery, and other people [ecologists] don't. Some [ecologists] say that we can. Some say that we shouldn't. A lot of arguments come into play of, and this is actually one of the best arguments for this entire region, is what truly is restoration ecology. Are we restoring it? And what are we restoring it to? (10/18/10, MD, land manager).

We thus built psychological or behavioral attributes and mechanisms (entrenchment and cost of dissent) into the model, and tested how they might result in more varied position trajectories and decision outcomes than what structural mechanisms alone could accomplish.

\section{Complex model simulations}

To understand how entrenchment and cost of dissent affect decision processes and outcomes we conducted a second series of stylized scenarios:

- Scenario C1: base model

- Scenario C2: cost of dissent only

- Scenario C3: entrenchment only

- Scenario C4: entrenchment and cost of dissent

We used the same settings as in the base model (Table 1) with the exception of the mutation rate, which we set at 10 per mil, based on our observations of its effects in the base model.

\section{Effect of entrenchment and cost of dissent}

Regardless of the number of groups, none of the combinations of cost of dissent and entrenchment significantly affected the average collective position, which is similar to the simulations with the base model. Cost of dissent and entrenchment had a greater impact on the standard deviation in the collective position across runs (Fig. 9a). That is, while the collective position averaged across runs did not differ much from the base model, individual runs were more divergent from 0.5. cost of dissent alone (Scenario 7) produced a slightly lower standard deviation in collective position, explained by the fact that cost of dissent helps facilitate agreement at the end of the run (Fig. 10a). Compared to Scenario $\mathrm{C} 1$, the added entrenchment in Scenarios C3 and C4 increased the standard deviation of collective position, i.e., more variety was produced in collective position across runs. A possible 
explanation for this effect is that entrenchment introduces greater path dependence. In other words, early interactions affect future interactions, drawing the trajectory of the collective positions in different directions, sometimes away from the central values (Fig. 10b and 10c), compared to runs with no entrenchment (Fig. 8a and 10a). If enough agents follow the entrenched positions, then cost of dissent will effectively "seal the deal" (Fig. 10c), attracting other agents who may originally be far from the entrenched value.

Fig. 9. Effect of the cost of dissent (CoD) and entrenchment on: (a) collective position and (b) spread of individual positions. Error bars are $+1 \mathrm{SD}$.
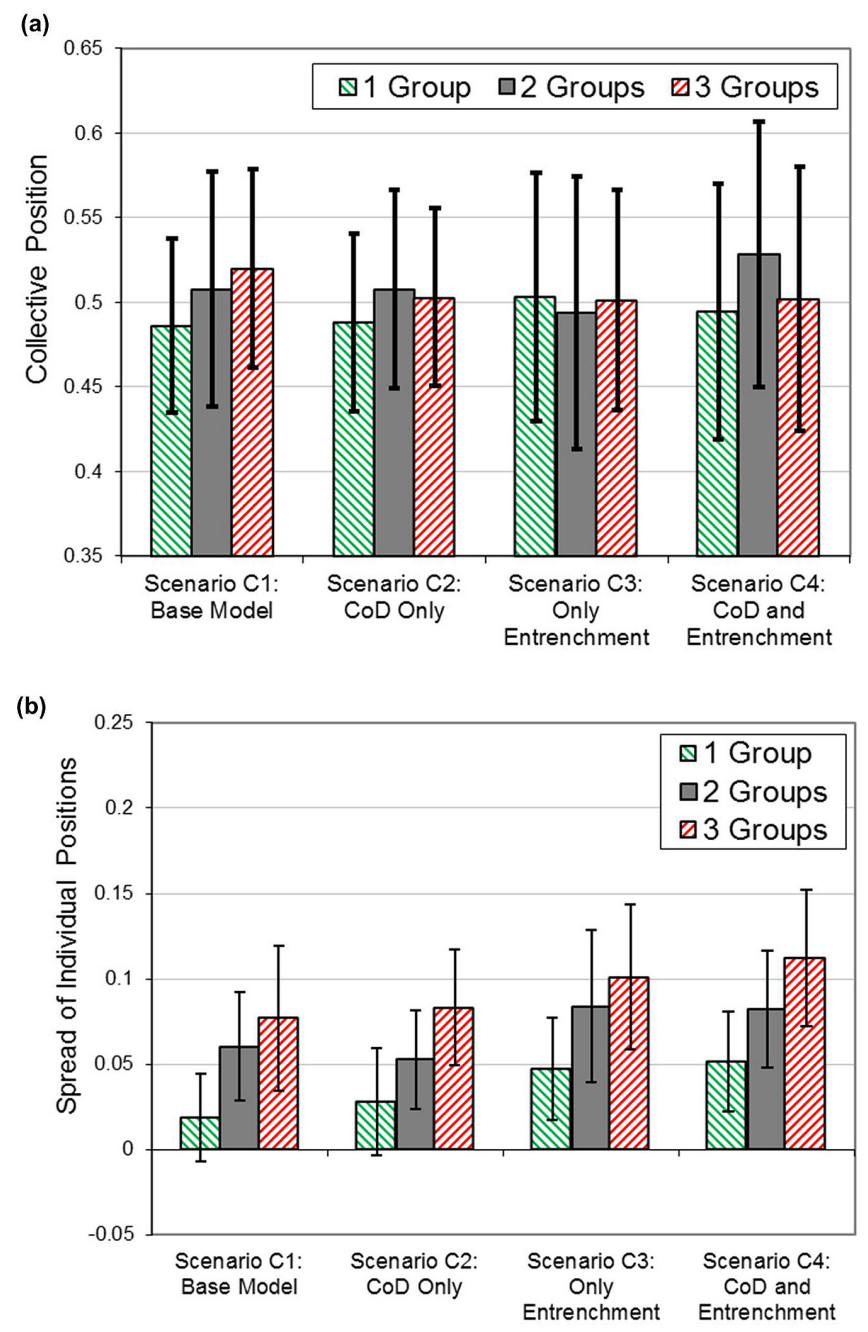

We observed similar effects on spread of individual positions within runs (Fig. 9b). Cost of dissent alone had less of an impact than entrenchment alone. When both are active, however, they reinforce the increased spread of positions among agents, as clusters of positions may form around
Fig. 10. Evolution of individual positions in two groups across cost of dissent and entrenchment scenarios with a 10\% mutation rate: (a) Scenario C2, (b) Scenario C3, and (c) Scenario C4. Dotted green line indicates period of the run during which cost of dissent occurs. Blue squares show examples of agents affected by cost of dissent. Turquoise dotted-line overlay indicates duration of agent entrenchment.
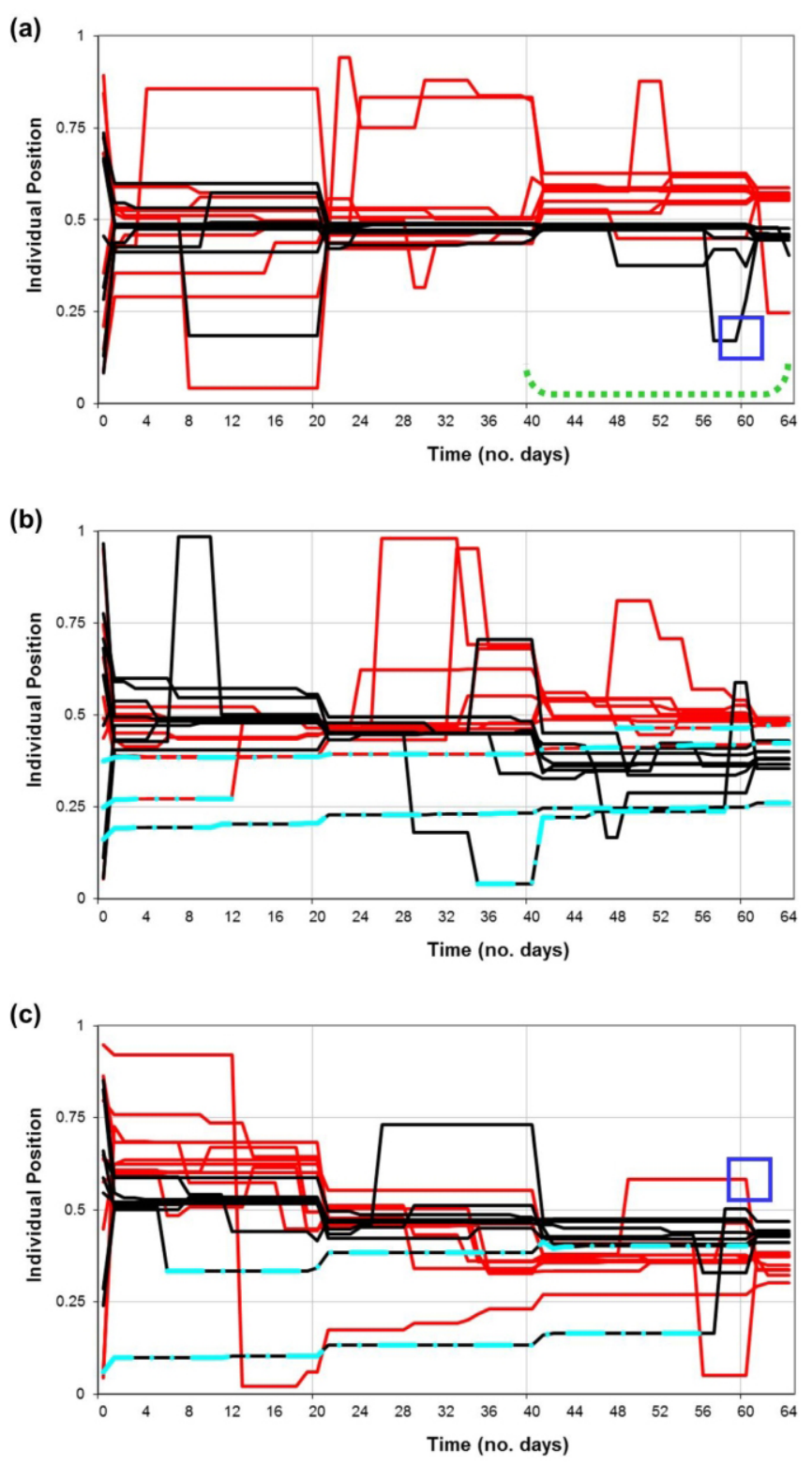

entrenched values when those averse to dissent interact with entrenched agents.

Overall, point-person consensus was the dominant decision strategy across all scenarios, with outcome frequencies of at 
least $87 \%$. Adding entrenchment reduces the likelihood of whole-group convergence and increases the likelihood of outside arbiter decisions, particularly with multiple groups, as it promotes divergence of opinions. When cost of dissent is added to entrenchment, outside arbitration never occurs because, despite the initial divergence introduced by entrenchment, cost of dissent may promote convergence around entrenched values.

\section{Effect of entrenchment and cost of dissent with position polarization}

To examine the effect of entrenchment and cost of dissent in scenarios where position distributions were polarized, we ran the complex model with polarized positions within one, two, or three groups (intragroup polarization) and polarized positions between two groups (intergroup polarization). The results obtained for spread of individual positions and frequency of decision strategies were not very different from those obtained for the polarization scenarios run with the base model. Differences are more noticeable within runs (Fig. 11), where psychological mechanisms cause slightly more divergence of positions among agents than with the base model (Fig. 8). This effect, however, is not strong enough to change the aggregate trends observed in the polarization scenarios run with the base model.

\section{DISCUSSION AND IMPLICATIONS FOR COLLECTIVE DECISION MAKING}

Arrow et al. (2000) argue that to understand the consensusbuilding process it is important to know the rules that each group has established with respect to how: (1) members present their claims to the group, (2) member's claims or point of view are evaluated and weighted compared to the claims or opinions of others, (3) disparate interests are reconciled and by whom, and (4) by whom a group decision will be established when group consensus is required and members' views diverge. Our models addressed each of these components through the following features: (1) group structure and several types of meetings, (2) "respect" as a measure of how well one's positions are transferred, (3) the role of "point persons," and (4) alternative decision strategies when whole-group convergence is not reached. Each of these features is supported by both literature and ethnographic information about Chicago Wilderness organizations.

We derived several important insights from the base model about the influence of structural components on decision making. If whole-group convergence is an organizational goal, particularly within a certain time period, our model suggests that both intragroup and intergroup formal meetings are important. This is especially true when the organization is structured into multiple groups, when new information affects the opinions of participants, and when different cultures exist across groups. As much as these mechanisms may promote convergence, however, it is still more likely that under these
Fig. 11. Evolution of individual positions in two groups across polarization scenarios with cost of dissent and entrenchment with a 10\% mutation rate: (a) intragroup polarization and (b) intergroup polarization. Turquoise dotted-line overlay indicates duration of agent entrenchment. Solid arrows show formal interactions (Note: only some meetings are indicated.)
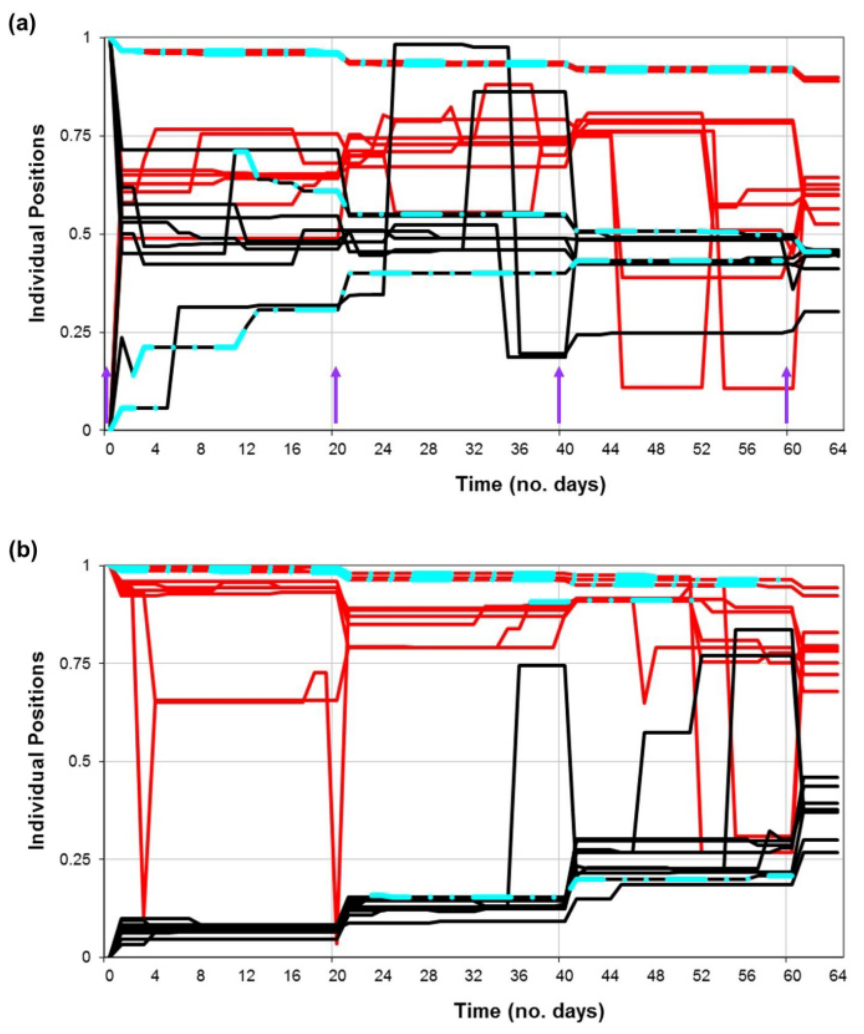

conditions point persons will need to negotiate decisions or even defer to outside arbiters to facilitate the decision-making process. Our model encourages formal, periodic face-to-face discussion amongst all actors involved in ecological restoration planning, yet an authority figure is still needed to move the process to an actual decision as diversity of structures, information, and opinions increases. The assumptions in our model that determine the threshold for intervention of point persons or outside arbiters were calibrated to match our observations, but will need to be reexamined with in-depth empirical data collection and analysis to understand the conditions in which specific decision strategies are activated. In particular, we will focus on identifying the characteristics of key figures at each level and their role in influencing the learning process and in activating specific decision strategies. Additionally, we assumed a number of workdays per season, representing weekdays. 
However, some organizations work mostly during weekends, suggesting the need to explore the effect of more sporadic interactions on the decision outcomes and trajectories. Further analysis of our empirical data will guide model reformulations and scenario design to explore these effects.

The psychological attributes in the complex model offer a richer explanation for variation in the trajectories of the decision-making process. Entrenchment alone, and in combination with cost of dissent, can prevent whole-group convergence, and create conflict and uncertainty in the collective position of a group at the end of a season by amplifying the divergence produced by other mechanisms. While new information and psychological attributes both introduce opportunities for innovation, the latter appear to be a greater hindrance to group convergence than the former. If an organization strives to prevent decision strategies in which group members lose their ability to contribute to the final decision, group leaders may have to balance entrenchment with the value they place on decisions made by all members of the group. The model suggests new directions for additional empirical research to reveal whether and how leaders facilitate the consideration of multiple positions and the incorporation of innovation, and determine the effects, if any, these strategies have on biodiversity outcomes.

Averaging across all runs for each scenario, the collective positions to which the group converged was 0.5 , even though singular runs did converge towards different values. This result is an artifact of our model setup; initial position randomization or polarization sets the collective value around 0.5 at the start of each run. The more complex model reduced the likelihood of a collective position of 0.5 occurring. Future efforts in in-depth empirical data collection will inform the initial position setup, which will likely lead to greater variation in the final position value (see below). Still, we propose that that convergence around the initial collective position has some empirical validity. In ecological restoration, as in many other collective processes, there is a substantial lag time between a decision and its observable impacts. Additionally, the complexity of social-ecological systems makes it difficult to isolate the ecological effects of specific restoration decisions. Time lags (in which the effect of decision is not felt for days, months, or even years) and complexity introduce uncertainty, which is represented in the random or polarized position scenarios. Uncertainty tends to promote the status quo (Samuelson and Zeckhauser 1988), as structural and psychological mechanisms dilute shifts in position, and reduce the possibility of big changes in group decisions. This barrier could be overcome with the use of complementary ecological models showing the biodiversity impacts of specific management decisions during collective discussions.

Our results provide strong motivation for field-testing structural and behavioral decision-making mechanisms. The current model is guiding systematic data analysis of interviews to develop and test new, case-specific mechanisms and scenarios. The IAD framework (see Ostrom 2007) will continue to help identify the specific institutional setup (rules and norms) of each organization. These setups include prescriptions about actors' positions and qualifications, how actors negotiate shared control over a decision, and the ways in which information "flows" among individuals and groups and within groups. Furthermore, both conventional and directed qualitative content analysis (Bernard 2005, Hsieh and Shannon 2005) and Nvivo coding (Strauss and Corbin 1990) will elucidate details like which agent type experiences a mutation, entrenchment, or cost of dissent, and at what point during the decision-making season. This analysis will also allow us to understand how institutional memory influences long-term decision-making processes in ecological restoration. We will also explore additional setups and mechanisms that might cause the final collective position to shift from the initial collective position by informing initial position values, targeting specific agents (point person versus advisor) for mutations and entrenchment at specific times, and by specifying how the new information is integrated in the collective deliberation. With these empirically informed extensions to our model, we will develop robust explanations for a variety of cases by explicitly linking decision outcomes to specific types of management styles. Ultimately, our work will provide recommendations to improve or develop collective decision-making structures and processes that reduce conflict and enhance biodiversity.

Responses to this article can be read online at: http://www.ecologyandsociety.org/issues/responses. php/5497

\section{Acknowledgments:}

This research was funded by the National Science Foundation Coupled Human-Natural Systems program (DEB-BE-0909451). We are grateful to our colleagues in the RESTORE research group funded by this grant, who provided valuable feedback of the modeling work and early versions of this article.

\section{LITERATURE CITED}

Anderson, C. A., M. Lepper, and L. Ross. 1980. Perseverance of social theories: the role of explanation in the persistence of discredited information. Journal of Personality and Social Psychology 39:1037-1049.

Anderson, C. A., and J. J. Lindsay. 1998. The development, perseverance, and change of naive theories. Social Cognition 16:8-30. http://dx.doi.org/10.1521/soco.1998.16.1.8 
Andersson, K. 2006. Understanding decentralized forest governance. Sustainability: Science, Practice, \& Policy 2 (1):25-35.

Argyres, N., and V. Mui. 2007. Rules of engagement, credibility, and the political economy of organizational dissent. Strategic Organization 5(2):107-154. http://dx.doi. org/10.1177/1476127007078502

Arrow, H., J. E. McGrath, and J. L. Berdahl. 2000. Small groups as complex systems: formation, coordination, development and adaptation. Sage, Thousand Oaks, California, USA.

Atran, S., D. Medin, N. Ross, E. Lynch, V. Vapnarsky, E. Ucan Ek', J. Coley, C. Timura, and M. Baran. 2002. Folk ecology, cultural epidemiology, and the spirit of the commons. A garden experiment in the Maya Lowlands, 1991-2001. Current Anthropology (43)3:421-450.

Baumann, M. R., and B. L. Bonner. 2004. The effects of variability and expectations on utilization of member expertise and group performance. Organizational Behavior and Human Decision Processes 93(2):89-101. http://dx.doi.org/10.1016/ j.obhdp.2003.12.004

Becu, N., A. Neef, P. Schreinemachers, and C. Sangkapitux. 2008. Participatory computer simulation to support collective decision-making: potential and limits of stakeholder involvement. Land Use Policy 25(4):498-509. http://dx.doi. org/10.1016/j.landusepol.2007.11.002

Beratan, K. 2007. A cognition-based view of decision processes in complex social-ecological systems. Ecology and Society 12(1):27. [online] URL: http://www.ecologyandsociety. org/vol12/iss $1 / \operatorname{art} 27 /$.

Bernard, R. 2005. Research methods in anthropology: qualitative and quantitative approaches. AltaMira Press, Lanham, Maryland, USA.

Budescu, D. V., and A. K. Rantilla. 2000. Confidence in aggregation of expert opinions. ACTA Psychologica 104:37198. http://dx.doi.org/10.1016/S0001-6918(00)00037-8

Castella, J. C. 2009. Assessing the role of learning devices and geovisualization tools for collective action in natural resource management: Experiences from Vietnam. Journal of Environmental Management 90(2):1313-1319.

Che, Y., and N. Kartik. 2009. Opinions as incentives. Journal of Political Economy 117(5):815-8808. http://dx.doi. org/10.1086/648432

Chhatre, A., and A. Agrawal. 2009. Trade-offs and synergies between carbon storage and livelihood benefits from forest commons. Proceedings of the National Academy of Sciences of the United States of America 106(42):17667-17670. http:// dx.doi.org/10.1073/pnas.0905308106
Conradt, L., and T. J. Roper. 2009. Conflicts of interest and the evolution of decision sharing. Philosophical Transactions of the Royal Society-Biological Sciences 364(1518):807-819. http://dx.doi.org/10.1098/rstb.2008.0257

Crane, P., L. Heneghan, F. Muraski-Stotz, M. Pruett-Jones, L. Ross, A. Wali, and L. Westphal. In press. Chicago wilderness: integrating biological and social diversity in the urban garden. In K. Morrison, S. Hetch, and C. Padoch, editors. The social life of forests: new frameworks for studying change. The University of Chicago Press, Chicago, Illinois, USA.

Dane, E. 2010. Reconsidering the trade-off between expertise and flexibility: a cognitive entrenchment perspective. Academy of Management Review (35)4:579-603. http://dx. doi.org/10.5465/AMR.2010.53502832

Davis, J. H. 1996. Group decision making and quantitative judgments: a consensus model. Pages 35-59 in E. Witte, and J. H. Davis, editors. Understanding group behavior: consensual action by small groups. Erlbaum, Mahwah, New Jersey, USA.

Davis, J. H., M. F. Stasson, C. D. Parks, L. Hulbert, T. Kameda, S. K. Zimmerman, and K. Ono. 1993. Quantitative decisions by groups and individuals: voting procedures and monetary awards by mock civil juries. Journal of Experimental Social Psychology 29:326-46. http://dx.doi.org/10.1006/jesp.1993.1015

Delre, S. A., W. Jager, T. H. A. Bijholt, and M. A. Janssen. 2010. Will it spread or not? The effects of social influences and network topology on innovation diffusion, Journal of Product Innovation Management 27:267-282.

Dryzek, J. S., and C. List. 2003. Social choice theory and deliberative democracy: a reconciliation. British Journal of Political Science 33(1):1-28. http://dx.doi.org/10.1017/ $\underline{\text { S0007123403000012 }}$

Ekel, P. Y., J. S. Martini, and R. M. Palhares. 2008. Multicriteria analysis in decision making under information uncertainty. Applied Mathematics and Computation 200:501-516. http://dx.doi.org/10.1016/j.amc.2007.11.024

Gibson, C., M. A. McKean, and E. Ostrom, editors. 2000. People and forests: communities, institutions, and governance. MIT Press, Cambridge, Massachusetts, USA.

Gilbert, N., and K. Troitzsch. 1999. Simulation for the social scientist. Open University Press, Philadelphia, Pennsylvania, USA.

Glaser, B. G., and A. L. Strauss. 1967. The discovery of grounded theory: strategies for qualitative research. Aldine Publishing Company, Chicago, Illinois, USA. http://dx.doi. org/10.1097/00006199-196807000-00014

Glennemeier, K. 2004. The state of our wooded lands: results from the Chicago Wilderness Woods Audit. Chicago Wilderness Journal 2(2):16-22. 
Gobster, P., and B. Hull, editors. 2000. Restoring nature: perspectives from the social sciences and humanities. Island Press, Washington, D.C.

Goldstone, R. L., and M. A. Janssen. 2005. Computational models of collective behaviour, Trends in Cognitive Science 9(9): 424-430.

Grimble, R., and K. Wellard. 1997. Stakeholder methodologies in natural resource management: a review of principles, contexts, experiences and opportunities. Agricultural Systems 55(2):173-193. http://dx.doi.org/10.1016/ $\underline{\text { S0308-521X(97)00006-1 }}$

Haefner, J. W. 1996. Modeling biological systems: principles and application. Chapman and Hall, London, UK.

Hardy, S. D., and T. M. Koontz. 2009. Rules for collaboration: institutional analysis of group membership and levels of action in watershed partnerships. Policy Studies Journal 37 (3):393-414. http://dx.doi.org/10.1111/j.1541-0072.2009.00320. $\underline{\mathrm{X}}$

Harvey, N., C. Harries, and I. Fischer. 2000. Using advice and assessing its quality. Organizational Behavior and Human Decision Processes 81:252-73. http://dx.doi.org/10.1006/ obhd.1999.2874

Hayati, D., B. Abadi, R. Movahedi, and M. Heidari. 2009. An empirical model of factors affecting farmers' participation in natural resources conservation programs in Iran. Journal of Food Agriculture and Environment 7(1):201-207.

Henrich, J., and F. Gil-White. 2001. The evolution of prestige. Evolution and Human Behavior 22:165-96. http://dx.doi. org/10.1016/S1090-5138(00)00071-4

Herath, G., and T. Prato. 2006. Role of multi-criteria decision making in natural resource management. Pages 1-10 in G. Herath, and T. Prato. editors. Using multi-criteria decision analysis in natural resource management. Ashgate, Burlington, Vermont, USA.

Hermans, C., J. Erickson, T. Noordeweir, A. Sheldon, and M. Kline. 2007. Collaborative environmental planning in river management: An application of multicriteria decision analysis in the White River Watershed in Vermont. Journal of Environmental Management 84(4):534-546. http://dx.doi. org/10.1016/j.jenvman.2006.07.013

Hopthrow, T., and L. G. Hulbert. 2005. The effect of group decision making on cooperation in social dilemmas. Group Processes and Inter-group Relations 8(1):89-100. http://dx. doi.org/10.1177/1368430205049253

Hsieh, H., and S. Shannon. 2005. Three approaches to qualitative content analysis Qualitative Health Research 15 (9):1277-1288.

Imperial, M. T. 1999. Analyzing institutional arrangements for ecosystem-based management: lessons from the Rhode
Island salt ponds SAM plan. Coastal Management 27(1): 31-56. http://dx.doi.org/10.1080/089207599263884

Ito, N., K. Takeuchi, K. Kuriyama, S. Yasushi, T. Takahiro, and Y. Mitani. 2008. The influence of decision-making rules on individual preferences for ecological restoration: evidence from an experimental survey. Ecological Economics 68: 2426-2431. http://dx.doi.org/10.1016/j.ecolecon.2009.03.022

Janssen, M., and E. Ostrom. 2006. Governing socialecological systems. Pages 949-1011 in L. Tesfatsion, and K. L. Judd, editors. Handbook of computational economics. North-Holland, Amsterdam, Netherlands. http://dx.doi. org/10.1016/S1574-0021(05)02030-7

Jones, N. A., P. Perez, T. G. Measham, G. J. Kelly, P. d'Aquino, K. A. Daniell, A. Dray, and N. Ferrand. 2009. Evaluating participatory modeling: developing a framework for cross-case analysis. Environmental Management 44 (6):1180-1195.

Kerr, N. L., and R. S. Tindale. 2004. Group performance and decision making. Annual Review of Psychology 55:623-55. http://dx.doi.org/10.1146/annurev.psych.55.090902.142009

Kilduff, M., and D. Krackhardt. 1994. Bringing the individual back in: a structural analysis of the internal market for reputation in organizations. Academy of Management Journal 37(1):87-108.

Lal, P., H. Lim-Applegate, and M. Scoccimarro. 2001. The adaptive decision-making process as a tool for integrated natural resource management: focus, attitudes, and approach. Ecology and Society 5(2):11. [online] URL: http://www. ecologyandsociety.org/vol5/iss2/art11/manuscript.html.

Landier, A., D. Sraer, and D. Thesmar. 2009. Optimal dissent in organizations. The Review of Economic Studies 76:761-794.

Locke, K., K. Golden-Biddle, and M. S. Feldman. 2008. Making doubt generative: rethinking the role of doubt in the research process. Organization Science 19:907-918.

Macy, M. W., and R. Willer. 2002. From factors to actors: computational sociology and agent-based modeling. Annual Review of Sociology 28(1): 143-166.

Maturo, A., and A. G. S. Ventre. 2010. Reaching consensus in multiagent decision making. International Journal of Intelligent Systems 25(3):266-273.

Meyer, T. A., W. A. Labuschagne, and J. Heidema. 2000. Refined epistemic entrenchment. Journal of Logic, Language and Information (9)2:237-259.

Moskovits D. K., C. Fialkowski,G. M. Mueller, T. A. Sullivan, J. Rogner, and E. McCance. 2004. Chicago Wilderness: a new force in urban conservation. Annals of the New York Academy of Sciences 1023:215-36. 
Mulford, M., L. Jackson, and H. Svedsäter. 2008. Encouraging cooperation: revisiting solidarity and commitment effects in prisoner's dilemma games. Journal of Applied Psychology 38 (12):2964- 2989.

Ohtsubo, Y., and A. Masuchi. 2004. Effects of status difference and group size in group decision making. Group Processes and Inter-group Relations 7(2):161-172.

Ostrom, E. 2007. Institutional rational choice. Pages 21-64 in P. Sabatier, editor. Theories of the policy process. Second edition Westview, Boulder, Colorado, USA. http://dx.doi. org $/ 10.2307 / 1962889$

Poteete, A., and E. Ostrom. 2008. Fifteen years of empirical research on collective action in natural resource management: struggling to build large- $\mathrm{N}$ databases based on qualitative research. World Development 36(1):176-195. http://dx.doi. org/10.1016/j.worlddev.2007.02.012

QSR International Pty Ltd. 2010. NVivo 9 [qualitative data analysis software]. Melbourne, Victoria, Australia.

Railsback, S., and V. Grimm. 2012. Agent-based and individual-based modeling: a practical introduction. Princeton University Press, Princeton, New Jersey, USA.

Regan, H. M., M. Colyvan, and L. Markovchick-Nicholls. 2006. A formal model for consensus and negotiation in environmental management. Journal of Environmental Management 80:167-176. http://dx.doi.org/10.1016/j.

jenvman.2005.09.004

Robinson D. T., D. G. Brown, D. C. Parker, P. Schreinemachers, M. A. Janssen, M. Huigen, H. Wittmer, N. Gotts, P. Promburom, E. Irwin, T. Berger, F. Gatzweiler, and C. Barnaud. 2007. Comparison of empirical methods for building agent-based models in land use science. Journal of Land Use Science 2(1):31-55. http://dx.doi.org/10.1080/17474230701201349

Samuelson, W., and R. Zeckhauser. 1988. Status quo bias in decision-making. Journal of Risk and Uncertainty 1:7-59. http://dx.doi.org/10.1007/BF00055564

See, K. E. 2009. Reaction to decision with uncertain consequences. Journal of Personality and Social Psychology 96(1):104-118. http://dx.doi.org/10.1037/a0013266

Sniezek, J. A. 1992. Groups under uncertainty: an examination of confidence in group decision making. Organizational Behavior and Human Decision Processes 62:159-74. http:// dx.doi.org/10.1006/obhd.1995.1040

Sniezek, J. A., and T. Buckley. 1995. Cueing and cognitive conflict in judge-advisor decision making. Organizational Behavior and Human Decision Processes 62:159-174.

Steyaert, P., M. Barzman, J. P. Billaud, H. Brives, B. Hubert, G. Ollivier, and B. Roche. 2007. The role of knowledge and research in facilitating social learning among stakeholders in the French Atlantic coastal wetlands. Environmental Science \& Policy 10(6):537-550. http://dx.doi.org/10.1016/j. envsci.2007.01.012

Strauss, A., and J. Corbin. 1990. Basics of qualitative research: grounded theory procedures and techniques. Sage, London, UK.

Taylor, K.A., and A. Short. 2009. Integrating scientific knowledge into large-scale restoration programs: the CALFED Bay-Delta Program experience. Environmental Science \& Policy 12(6):674-683. http://dx.doi.org/10.1016/j. envsci.2009.07.001

Thomas-Hunt, N. C., T. Y. Ogden, and M. A. Neale. 2003. Who's really sharing? Effects of social and expert status on knowledge exchange within groups. Management Science 49 (4):464-477.

White R. M., A. Fischer, K. Marshall, J. M. J. Travis, T. J. Webb, S. di Falco, S. M. Redpath, and R. van der Wal. R. 2009. Developing an integrated conceptual framework to understand biodiversity conflicts. Land Use Policy 26:242253. http://dx.doi.org/10.1016/j.landusepol.2008.03.005

Wilensky, U. 1999. NetLogo. Center for Connected Learning and Computer-Based Modeling, Northwestern University, Evanston, Illinois, USA. [online]. URL: http://ccl. northwestern.edu/netlogo/.

Wittenbaum, G. M. 1998. Information sampling in decisionmaking groups: the impact of members' task-relevant status. Small Group Research 29:57-84. http://dx.doi. org/10.1177/1046496498291003

Wittenbaum, G. M. 2000. The bias toward discussing shared information: why are high-status group members immune? Community Research 27:379-401.

Yang, L., and N. Gilbert. 2008. Getting away from numbers: using qualitative observation for agent-based modeling. Advances in Complex Systems 11(2):175-185 http://dx.doi. org/10.1142/S0219525908001556

Yaniv, I., and E. Kleinberger. 2000. Advice taking in decision making: egocentric discounting and reputation formation. Organizational Behavior and Human Decision Processes 83 (2):260-281. http://dx.doi.org/10.1006/obhd.2000.2909

Zellner, M. L. 2008. Embracing complexity and uncertainty: the potential of agent-based modeling for environmental planning and policy. Planning Theory and Practice 9(4):437457. http://dx.doi.org/10.1080/14649350802481470 